\title{
Does higher energy efficiency lower economy-wide energy use?
}

\section{Working Paper}

\section{Author(s):}

Rausch, Sebastian; Schwerin, Hagen

Publication date:

2018-10

Permanent link:

https://doi.org/10.3929/ethz-b-000298513

Rights / license:

In Copyright - Non-Commercial Use Permitted

Originally published in:

Economics Working Paper Series 18/299 


\section{CER-ETH - Center of Economic Research at ETH Zurich}

Does Higher Energy Efficiency Lower Economy-Wide Energy Use?

S. Rausch and H. Schwerin

Working Paper 18/299

October 2018

Economics Working Paper Series

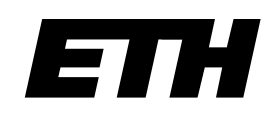

Eidgenössische Technische Hochschule Zürich Swiss Federal Institute of Technology Zurich 


\title{
Does Higher Energy Efficiency Lower Economy-Wide Energy Use?
}

\author{
By Sebastian Rausch and Hagen Schwerin* \\ OCTOBER 2018
}

\begin{abstract}
We develop a general equilibrium growth model with capital and energy use to examine the hypothesis that economy-wide energy use increases with energy efficiency. To obtain energy use that would have occurred in the absence of energy efficiency changes, chosen energy efficiency is induced by technological change. Viewing technological change in form of changes in the cost of capital and energy producing energy services enables us to control for the sources of energy efficiency improvements in a counterfactual setting. Calibrating the model to the post-WWII U.S. economy, we find that higher energy efficiency increased rather than reduced energy use, because lower capital cost enhanced energy use by more than the increase in energy cost reduced it. This casts strong doubts on the view that energy-saving technological change has lowered fossil energy use. (JEL D13, E23, O30, O41, Q43)
\end{abstract}

Increases in energy efficiency are widely viewed as reducing energy use and can thus help to address some of the major challenges related to fossil fuels: limiting carbon dioxide emissions to mitigate climate change, lowering "local" air pollution to yield health benefits, and enhancing the security of energy supply. Using equipment capital that is more energyefficient - for example, more fuel-efficient vehicles or less electricity-consuming appliancesdiscourages the associated energy use, yielding energy "savings." This standard thinking is correct when the amount of services produced with energy is viewed as being fixed. But the lower implicit cost of energy services at the same time induces a higher demand for equipment entailing the possibility of an energy "rebound", i.e. an increase in energy use due to more energy-efficient equipment. In his famous book The Coal Question, Jevons (1865, p. 141) maintained that "It is the very economy of its [coal's] use which leads to its extensive consumption." ${ }^{1}$ That energy use overall increases in response to greater energy efficiency has become known as the energy efficiency (or Jevons') paradox hypothesizing that energy rebound exceeds energy savings.

Although Jevons' paradox raises doubt about the role of energy efficiency - and more fundamentally about the role of technological advances - for addressing the challenges of fossil fuel use, surprisingly little is known about the central and long-standing question it poses: how has economy-wide energy use responded to energy efficiency improvements? The

\footnotetext{
* Rausch: Center of Economic Research at ETH Zurich, Switzerland, and Joint Program on the Science and Policy of Global Change, Massachusetts Institute of Technology, USA (email: srausch@ethz.ch). Schwerin: Center of Economic Research at ETH Zurich, Switzerland (email: hschwerin@ethz.ch). This research is part of the activities of SCCER CREST, which is financially supported by the Swiss Innovation Agency (Innosuisse).

${ }^{1}$ British coal consumption soared following the deployment of James Watt's improved coal-fired steam engine. Jevons' concern was the sustainability of coal use which, in his view, was intimately linked to England's economic prosperity.
} 
literature - as, for example, reviewed in Gillingham, Rapson, and Wagner (2016), Michaels (2012), and Greening, Greene, and Difiglio (2000) - has examined the question of energy rebound without specifying technological sources for energy efficiency improvements, and has predominantly studied energy rebounds at the household- or industry-level. Analyzing Jevons' paradox however requires a framework with technology-induced energy efficiency and general equilibrium effects. This paper is the first to provide such a framework. ${ }^{2}$

In our dynamic model, we separate the change in energy use over time into effects of technological change on energy services (rebound) and energy efficiency (savings) in a counterfactual setting that helps examine the level of energy use which would have prevailed in the absence of technological change that has occurred. To create a counterfactual situation of constant energy efficiency in an empirical assessment, one needs a theory of energy use which links a change in energy efficiency (and energy services demanded) to technological change that can be observed and varied counterfactually. We thus develop a general equilibrium model of energy services growth with energy and capital efficiency rates induced by technological change. Linking technological change to observable changes in the cost of energy and capital in the production of energy services enables us to control for the sources of endogenous energy efficiency improvements in a counterfactual setting.

Our growth model has three main elements. First, the production of energy services requires combining capital with energy such that energy efficiency defined as energy services per unit of energy use is positively related to the capital-energy ratio. Changes in capital and energy cost then affect the growth of chosen energy efficiency. Viewing these technological changes as exogenous enables us to analyze the counterfactual path of energy services that would have occurred without energy-saving technological change, which by definition raises energy efficiency. Second, the model posits Harrod-neutral technological change as a factor that has had a positive impact of economic growth and energy use. Third, to account for inertia in adjusting energy efficiency, energy services can be produced with capital varieties of energy (complementary capital and energy). These varieties have a capital-energy ratio that can only be chosen for new capital vintages, using a putty-clay framework similar to Atkeson and Kehoe (1999). The choice of these varieties, influenced by technological change, induces energy efficiency.

The model links technological progress, energy efficiency, and energy use. First, both lower capital and higher energy cost (relative to consumption) enhance energy efficiency, hence are energy-saving, because they increase the capital-energy ratio. Second, lower capital cost increases energy use while higher energy cost decreases energy use. As a result, we can express energy growth, or energy rebound and savings, by the rates of technological change. The representation of energy growth shows that the model accommodates both the case in which the energy efficiency paradox holds and the case in which it does not hold.

Whether or not the energy efficiency paradox can be obtained is thus a quantitative question.

${ }^{2}$ While we examine rebound to technological change, i.e. Jevons' paradox, other studies in the environmental economics literature have assessed rebound to public policies affecting energy efficiency. Examples include Levinson (2016) on a large-scale building insulation program, Davis, Fuchs, and Gertler (2014) on an appliance rebate program in Mexico, Fowlie, Greenstone, and Wolfram (2018) on building codes in California, and Jacobsen and van Benthem (2015) on tightened fuel efficiency standard on new vehicles. 
To empirically assess the paradox, we calibrate the model to US data on long-run output, capital, and energy growth for the 1960-2011 period. In our counterfactual experiment for examining the energy efficiency paradox, the equilibrium with inferred energy efficiency change is represented by the equilibrium balanced growth path matching the data for the 1960-2011 period. The counterfactual environment holds constant the capital and energy cost.

We find that long-run energy-saving technological change has increased energy efficiency, which in turn has promoted energy use. The potential reduction in energy use from energy efficiency improvements (i.e., the energy savings) has been overcompensated by the energy services response (i.e., the energy rebound). The reason is that a lower cost for new equipment capital enhanced energy use by more than higher energy costs reduced energy use. In our central case, we estimate an energy rebound of 102 percent of energy savings (i.e., a rebound rate of 1.02). While sensitivity analyses show that different estimates are possible, the estimates exceed 100 percent. The finding that energy rebound has exceeded energy savings is mainly driven by the relative magnitudes of the historical changes in capital and energy cost as well as the (calibrated) response of output with respect to the average energy efficiency of different vintages of energy-using capital. We find that both effects have led to significant growth in energy services per output in the market sector. In fact, our calibrated model shows that lower capital prices have been an engine for growth of energy. Equilibrium growth accounting shows that neutral technological change and a lower capital cost were the main drivers for energy growth contributing with 92 and 80 percent, respectively, whereas the increase in energy cost accounted for -72 percent.

Our finding that equipment-specific and energy cost changes over time have led rebound to exceed savings of energy use in the U.S. economy over the 1960-2011 period on average per year provides evidence supporting the energy efficiency paradox. This casts strong doubts on the view that energy-saving technological change lowered fossil energy use - and has thus contributed to addressing the challenges of fossil fuels related to climate change, local pollution, and energy security.

Our paper contributes to four areas of the literature. First, we add to work on energy rebound which covers both micro- (Binswanger, 2001; Borenstein, 2015) and macroeconomic approaches (Khazzoom, 1980; Brookes, 1990; Saunders, 1992; Wei, 2007; Lemoine, 2015). ${ }^{3}$ An important shortcoming of these studies is that energy efficiency improvements are viewed as being exogenous, i.e. the sources for improvements are left unspecified. This, however, precludes an investigation of the efficiency paradox as the sources underlying the efficiency improvements need to be represented and controlled for in a counterfactual experiment (Greening, Greene, and Difiglio, 2000). By developing a novel dynamic general equilibrium model with induced energy efficiency improvements that can be applied to observable changes in the cost of energy and energy-using equipment, we are able to provide, to the best of our knowledge, the first conceptual and empirical analysis of the energy

\footnotetext{
${ }^{3}$ Microeconomic approaches to studying energy rebound have been used to examine the substitution possibilities between consumption goods (Binswanger, 2001; Borenstein, 2015) while macroeconomic approaches have been used to investigate the energy consumption elasticity of energy efficiency in various functional forms (Khazzoom, 1980; Brookes, 1990; Saunders, 1992; Wei, 2007; Lemoine, 2015). These approaches have informed calculations of productspecific energy rebound with reduced-form analyses using estimated price elasticities of energy demand (see the review by Greening, Greene, and Difiglio, 2000; Gillingham, Rapson, and Wagner, 2016) as well as economy-wide rebound calculations with large-scale simulation models (see the review by Michaels, 2012).
} 
efficiency paradox from a macroeconomic perspective. As the energy efficiency paradox does or does not hold theoretically dependent on parameter values, our model overcomes the criticism by Gillingham, Rapson, and Wagner (2016) according to which assumptions in macroeconomic studies always imply the efficiency paradox.

Second, we contribute to the macroeconomic analysis of energy and growth, in particular perceptions of environmental policy and sources for energy-saving technological change. Our confirmation of the efficiency paradox for the post-WWII U.S. economy suggests that relying on technological advances alone may not reduce energy use to the extent needed to help address the environmental challenges of fossil energy. Instead, policies targeted at taxing dirty and promoting clean energy sources are required. This complements findings of other work that innovation does not automatically lead the efficient way between dirty and clean energy production technologies, instead policies intervening by directing innovation toward clean energy are warranted (Acemoglu, Aghion, Bursztyn, and Hemous, 2012; Acemoglu, Akcigit, Hanley, and Kerr, 2016) ${ }^{4}$ Without such policies, our analysis suggests that energy efficiency improvements do not necessarily contribute to environmental protection. We show that higher energy cost decreases energy use by raising energy expenditure and raising energy efficiency (and the capital intensity of energy), implying the possibility to reduce fossil energy use by increasing its user cost. We set up a model of energy efficiency induced by technological change comprised of capital and energy cost changes. Hassler, Krusell, and Olovsson (2012) examined the choice of economy-wide capital-labor and energy productivity with a production function taken to U.S. data. They postulated directed research effort as being the main determinant of asymmetric changes of capital-labor and energy productivity.

Third, we add to work on investment-specific technological change and putty-clay factor use. Greenwood, Hercowitz, and Krusell (1997) found that equipment-specific technological change contributed about 58 percent to per-capita output growth in the U.S. economy between 1955-1990. Our results suggest that investment-specific technological progress has diminished in importance relative to neutral technological change after 1990. In the putty-clay models of capital and energy use in Atkeson and Kehoe (1999) and Wei (2003), there is no growth. Gilchrist and Williams (1998) derive a balanced growth path for a putty-clay model with learning about productivity inducing underutilized capital and with no investment-specific technological change. We characterize the deterministic balanced growth path in a putty-clay model with fully utilized capital and investment-specific technological change, including of the technological gap of energy efficiency between the youngest vintages and average practice. Díaz and Puch (2013) used investment-specific technology to study the fluctuations in the energy expenditure, capital-energy ratio, and capital-output ratio in the business sector but did not investigate energy rebound.

Fourth, on a methodological level we extend previous studies on adjusting investmentspecific technological change and studying household energy use. To measure the change in

\footnotetext{
${ }^{4}$ Aghion, Dechezleprêtre, Hémous, Martin, and Van Reenen (2016) examined how the change in energy cost incurred for using gasoline-driven automobiles affects innovations in gasoline-driven versus electric-driven automobiles. In earlier papers, Popp (2002) and Newell, Jaffe, and Stavins (1999) studied product innovation in energy efficiency in response to energy price at a sectoral level. These studies showed that higher cost of energy used with equipment encourages innovation in equipment using alternative energy. Steinbuks and Neuhoff (2014) examined the choice of industry energy efficiency with a country panel of each of four industries. They found that higher energy cost increases the capital and material intensity of energy.
} 
the costs of energy-using capital, we extend Gordon's (1990) producer durable equipment price index over time using a price index of investment goods in the national income and product accounts in an autoregressive model. ${ }^{5}$ As a large fraction (about one half) of economy-wide energy use occurs in the household sector, we need to model business and household energy use - and for measurement of the model separate these in the data. To analyze the efficiency paradox for energy used in households, we extend the household production model of Greenwood and Hercowitz (1991) to include household energy services and energy use.

The remainder of the paper is organized as follows. Section I takes a first look at the data. Section II presents our model. Section III analyzes qualitative features of the model. Section IV describes our empirical strategy to take the model to the data. Section V presents and discusses our main quantitative results. Section VI analyzes a model extension with household production, and reports findings from sensitivity analyses and alternative counterfactual technological change. Section VII concludes. The Appendixes A and B and the Online Appendix contain additional material (including proofs, equilibrium conditions, and information on the construction of the data set used for model calibration).

\section{A First Look at the Data}

We begin by looking at the data to illuminate energy efficiency trends and identify possible drivers for them.

Efficiency gains in delivering capital-energy services have been well-documented for specific types of services. There have been numerous advances making energy-using capital less expensive compared to consumption. These include, for example, improvements in the internal combustion engine and transmission, insulation of buildings, and electrical appliances. Lighting has substantially increased in lumen per watt (Nordhaus, 1996) and automobiles have experienced increases in fuel economy controlling for size and power (Knittel, 2011). At the same time, data show an increase in the demand for services of illumination and miles driven with automobiles.

Looking at aggregate economy data, output and capital relative to energy use (from fossil and renewable forms together) have grown in the U.S. over the post-WWII period (see Figure 1A). This suggests an increase in energy efficiency, while at the same time aggregate energy use has increased (see Figure 1B). What are possible drivers or sources for the increase in energy efficiency?

The post-WWII data for the U.S. economy display two salient features. First, there has been a decline in the price of private nonresidential equipment and durable consumption goods, to the most part comprising energy-using capital-for example, vehicles, machines, electric appliances, and heating systems for buildings. Second, the price for energy, though fluctuating much, has moderately trended upward (Figure 1B). Both these price movements - which, because being expressed relative to a consumption deflator, can be viewed as reflecting technological change - are likely drivers for changes in the capitalenergy ratio, and hence energy efficiency improvements. This insight forms the basis for

\footnotetext{
${ }^{5}$ It is important that we develop a method to find the relative price of equipment investment and durable consumption goods as we use deflators from the NIPA published after the 2004 revisions. Cummins and Violante (2002) and Pakko (2002) adjusted disaggregated NIPA deflators published before the revisions.
} 
(A) CAPital-Energy and GNP-EnERgy Ratio

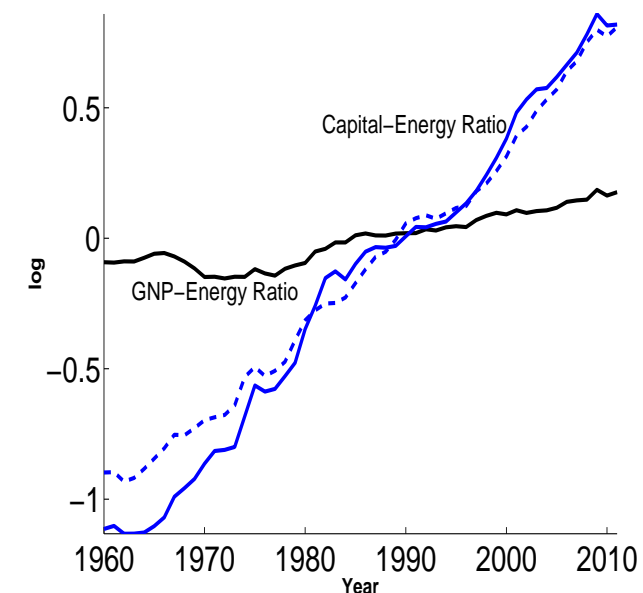

(B) Energy Use, Capital Prices, and Energy Price

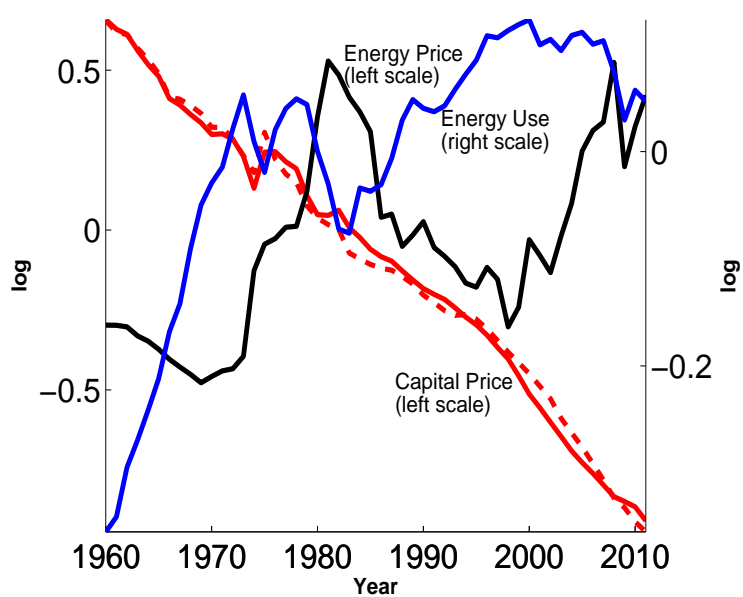

Fig 1. Relative Energy Use, Energy Use, and Prices (Businesses: Solid Curve, Households: Dashed Curve) U.S. Data 1960-2011: (A) Capital-Energy and GNP-Energy Ratio; (B) Energy Use, Capital Prices, AND ENERGy Price

Notes: The series are demeaned and in logarithms. See Appendix B for detail.

our analysis of the role of technological change for long-run energy use.

At the same time, it is important to control for other factors beside energy efficiency that have influenced energy use. Figures 1A and 1B show that GNP has largely co-moved with aggregate energy use suggesting a common source for a positive impact on economic growth and energy use.

\section{Model}

This section presents the basic idea underlying our investigation of the energy efficiency paradox, i.e. our experiment relating energy rebound and savings to technological change altering energy efficiency. We then specify the economic environment which is used for subsequent analysis by formulating an infinite-horizon discrete-time economy. To ease notation, we suppress a time subscript whenever no ambiguity arises.

\section{A. Basic Idea}

Assume that energy services $x$ can be produced by using at energy efficiency $\varphi$ according to

$$
x=\varphi u .
$$

Approaching the energy efficiency paradox with energy rebound and energy savings enables us to track the impact of technology on energy use. Energy savings measures how energy use responded to energy efficiency had energy services been unaffected by a change in energy efficiency. Energy rebound measures how energy use responded to a change in the energy services for a given level of energy efficiency. 
Decomposition of Energy Use into Rebound and Savings. - To express rebound and savings, we need to compare observed, or model-inferred, and counterfactual changes in energy efficiency and energy services (over a time period $[t, t+1]$ ). The change in energy efficiency and energy services are given by $\eta_{E, t+1} \equiv\left(\varphi_{E, t+1} / \varphi_{E, t}\right)$ and $\vartheta_{E, t+1} \equiv\left(x_{E, t+1} / x_{E, t}\right)$ in situation $E \in\{0,1\}$. We thus let $\eta_{1}$ and $\vartheta_{1}$ express observed, or model-inferred, energy efficiency and energy services. We let $\eta_{0}$ and $\vartheta_{0}$ denote the corresponding changes in a counterfactual situation.

Using the production function (1), the difference in the growth factor of energy use between observed and counterfactual economic outcomes $\left(\vartheta_{1} / \eta_{1}-\vartheta_{0} / \eta_{0}\right)$ can then be decomposed as follows:

$$
\vartheta_{1} / \eta_{1}-\vartheta_{0} / \eta_{0}=\underbrace{\left\{\vartheta_{1}-\vartheta_{0}\right\} \frac{1}{\eta_{1}}}_{\begin{array}{c}
\text { Energy Services Effect } \\
\text { on Energy Use } \\
\text { (Energy Rebound } r \text { ) }
\end{array}}-\underbrace{\vartheta_{0}\left\{\frac{1}{\eta_{0}}-\frac{1}{\eta_{1}}\right\}}_{\begin{array}{c}
\text { Energy Efficiency Effect } \\
\text { on Energy Use } \\
\text { (Energy Savings } s \text { ) }
\end{array}} .
$$

Energy savings $(s)$ express the change in energy use assuming no adjustment of energy services when energy efficiency changes. Thus, savings are the difference in the change of energy use over time between a hypothetical situation of counterfactual energy services and observed energy efficiency $\left(\vartheta_{0}\right.$ and $\left.\eta_{1}\right)$ and a situation of counterfactual energy services and efficiency $\left(\vartheta_{0}\right.$ and $\left.\eta_{0}\right)$, thus giving the energy efficiency effect on energy use. Energy rebound $(r)$ describes the adjustment of energy services when energy efficiency has changed. Thus, rebound equals the difference in the change of energy use between the hypothetical situation $\left(\vartheta_{0}\right.$ and $\left.\eta_{1}\right)$ and a situation of observed energy services and efficiency $\left(\vartheta_{1}\right.$ and $\eta_{1}$ ), giving the energy services effect on energy use. ${ }^{6}$

Technological Change.-Our decomposition of the change in energy use over time helps examine growth of energy use in the absence of technological change that has occurred (in contrast to examine energy use through technological change that might occur). Rebound and savings are identified through defining the counterfactual situation. Intuitively, the main counterfactual situation shuts off technological change that influences energy efficiency (meaning $\eta_{0}=1$ ), thus identifying rebound and savings. The energy efficiency paradox that energy rebound exceeds energy savings, $r>s$, then arises under a particular condition, thus far leaving open the direction of the change in energy efficiency observed (giving $\eta_{1}$ less than or greater than one).

The concepts of rebound and savings and the main counterfactual viewpoint make clear that examining the energy efficiency paradox is equivalent to investigating the response of energy use to technological change altering energy efficiency, i.e. the impact of technology on chosen $\varphi$. This provides the starting point for our analysis: to examine the efficiency paradox, we need to derive the changes over time in energy efficiency and energy services from a model in which these are induced through technological change, thus identifying rebound and savings. Importantly, we need a model which links energy efficiency improve-

\footnotetext{
${ }^{6}$ As in the literature, savings mean potential savings, so that rebound $(r)$ corresponds to potential savings $(s)$ less actual savings $\left(\vartheta_{0} / \eta_{0}-\vartheta_{1} / \eta_{1}\right)$. On a recent account of potential and actual savings, see Thomas and Azevedo (2013). On a similar definition of savings as an "energy efficiency effect", see Borenstein (2015).
} 
ments to technological change, which then can be defined as energy-saving technological change, to be able to create the counterfactual situations which define energy rebound and energy savings.

We investigate the question how technological change inducing energy efficiency improvements has affected long-run energy use by comparing balanced growth paths of our model. ${ }^{7}$ We next present an economic environment useful to investigate the energy efficiency paradox, that is, equation (2).

\section{B. The Economic Environment}

We study an environment with technological change altering energy efficiency which admits balanced growth representing long-run increases in energy efficiency.

Preferences.-All households on a continuum have preferences over consumption, $c$, and leisure, $(1-\ell)$, expressed by the expected discounted utility $V_{0}=\mathbb{E}_{0}\left[\sum_{t=0}^{\infty} \beta^{t} U\left(c_{t}, 1-\ell_{t}\right)\right]$ with the discount factor $\beta \in(0,1)$ and the expectation operator $\mathbb{E}_{0}$. The utility function

$$
U(c, 1-\ell)=\xi \ln c+(1-\xi) \ln (1-\ell)
$$

assumes a constant distribution parameter $\xi \in(0,1)$. In each period, households are endowed with one unit of time. Preferences are assumed as in Greenwood, Hercowitz, and Krusell (1997) so that there is a balanced growth path with constant labor supply. ${ }^{8}$ Labor supply $\ell$ is expressed as time used for production relative to available time which helps to control for population growth.

Production.-Output can be produced with the inputs of nonenergy-using capital $k$, energy services $x$, and labor $\ell$ according to

$$
y=G(k, x, z \ell)=k^{\alpha \gamma} x^{\alpha(1-\gamma)}(z \ell)^{1-\alpha},
$$

with the distribution parameters $0<\alpha, \gamma<1$ and exogenous labor efficiency $z>0$. Below we will specify the use of energy-using capital. We understand energy-using capital as physical capital that is used to transform energy from one form into another; for example, from our measured energy into captured energy that delivers services. The remainder of physical capital we then call nonenergy-using capital. Note that while nonenergy-using capital is not essential to formulate energy-saving technological change, a broad base of capital is, however, required for the empirical analysis of the efficiency paradox.

Energy services are produced with capital varieties and energy. Given the capital intensity of energy $v \in(0, \infty)$, energy-using capital units $m(v)$ require energy $m(v) / v$. The capital intensity can be chosen at the date of investment in capital and remains fixed thereafter. Energy efficiency is defined as the efficiency of energy in producing energy services, $f(v)=v^{\varepsilon}, 0<\varepsilon<1$. As variety-specific services $m(v) f(v) / v$ are produced with the

\footnotetext{
${ }^{7} \mathrm{~A}$ balanced growth analysis suits well the purpose of analyzing the efficiency paradox adopting a long-run economic perspective. Another advantage is that energy rebound and savings can be obtained without resorting to simulations. Examining how energy use has responded to energy-saving technological change in the short run, for example, with business cycle fluctuations, is beyond the scope of this paper and left for future research.

${ }^{8}$ The unitary elasticity of substitution between consumption and leisure allows a balanced growth path with constant labor supply. The value of the intertemporal elasticity of substitution, assumed equal to 1 (Log utility), does not affect results.
} 
efficiency of the factor capital $f(v) / v$, energy services and energy use are

$$
x=\int \frac{1}{v} m(v) f(v) \mathrm{d} v,
$$

$$
u=\int \frac{1}{v} m(v) \mathrm{d} v .
$$

More energy-efficient capital (described by higher $v$ ) is less productive (exhibits lower $f(v) / v)$ as in Atkeson and Kehoe (1999). ${ }^{9}$

To match the model to data with direct energy use in households, we introduce economywide energy use $e$. The portion of economy-wide energy use $\omega \in(0,1)$ households use without generating value for them, thus becomes wasted. Producing energy services thus requires energy use $u=(1-\omega) e^{10}$

The Laws of Motion.-Energy-using and nonenergy-using capital depreciate at the rate $\delta_{m}$ and $\delta_{k}$ and can be enhanced with investment $i_{m}(v)$ and $i_{k}$. With the number of new capital units per unit of output foregone $q$, energy-using capital evolves according to

$$
m^{\prime}(v)-\left(1-\delta_{m}\right) m(v)=q i_{m}(v) \geq 0,
$$

all $v \in(0, \infty)$. An increase in $q$ over time implies a declining unit cost of capital $(1 / q)$. Any new unit of nonenergy-using capital stock is created one-to-one using the consumption good, so that nonenergy-using capital evolves according to

$$
k^{\prime}-\left(1-\delta_{k}\right) k=i_{k} \geq 0 .
$$

Investment in capital of each type in each sector is irreversible, and hence nonnegative.

The Resource Constraint.-The exogenous price for energy $p$ reflects the unit cost of energy in terms of output. Output can thus be used for consumption, investment in capital stock, and energy acquisition pe,

$$
c+\int i_{m}(v) \mathrm{d} v+i_{k}+p e=y .
$$

We have made three changes to the standard one-sector growth model. The putty-clay structure of capital and energy makes energy a stock. The investment-specific technology can capture shifts in the productivity of factors creating energy-using capital relative to consumption. The energy cost can capture both the cost of domestic production of energy and import of energy. Importantly, note that our model treats $(1 / q)$ and $p$ as exogenously given.

In some large-scale macroeconomic models, energy and other production factors are

\footnotetext{
${ }^{9}$ To simplify exposition, we restrict here attention to the putty-clay assumption that the capital intensity of energy of any vintage is determined once. Section VI.B explores the implications of a chosen utilization of capital. We do not pose a minimum (or, Leontief) production function of services, as we assume that capital is fully utilized.

${ }^{10}$ An extension of the model to assess the efficiency paradox for direct energy use in households (see Section VI.A) includes households choosing their energy use.
} 
gross complements largely to have inertia in energy use in response to energy cost changes. We achieve this by means of a putty-clay production structure while maintaining the assumption of Cobb-Douglas for investments in energy-using capital (which we measure by equipment capital; see Section IV). For nonenergy-using capital (which we measure by structures capital; see Section IV), we do not assume a putty-clay structure. Our model thus embeds the view that there is a higher degree of substitutability between non-energy using capital and energy services as compared to the case for equipment and energy. This reflects the view that older structures can be better adjusted for their energy service use than older equipment. An example would be the retrofit of the existing building stock (e.g., roof or insulation) when energy service becomes more costly. In contrast, for capital equipment, complementarity means that the energy efficiency of existing capital is fixed (e.g., a refrigerator needs to be fully replaced, because it cannot be retrofitted).

\section{Equilibrium}

We analyze the energy efficiency paradox based on the equilibrium behavior of firms and households. Equilibrium has the following features.

Laws of Motion. We transform the laws of motion of energy intensity-specific capital into laws of motion of energy services and use (as in Atkeson and Kehoe (1999)) because we assume fully utilized capital,

$$
\begin{aligned}
& x^{\prime}-\left(1-\delta_{m}\right) x=\int \frac{f(v)}{v} q i_{m}(v) \mathrm{d} v, \\
& u^{\prime}-\left(1-\delta_{m}\right) u=\int \frac{1}{v} q i_{m}(v) \mathrm{d} v .
\end{aligned}
$$

Dynamic Firm Problem. Given the laws of motion, firm ownership of the capital that firms use allows to interpret energy services used by firms as being nontradable and makes firms pay for energy they use. Firms thus accumulate nonenergy-using capital, energy services, and energy and supply it to themselves. Households receive the profit of firms in the form of a dividend $\delta$ on equity shares $\tilde{s}$.

Government. To match both capital-output ratios and the real after-tax rate of return on capital in the model and data, a government is included in the decentralized economy. A government returns taxes on total dividends $\delta \tilde{s}$ and labor income $w \ell$ (with wage rate $w$ ) to households in the form of a lump-sum payment $\tau$. The tax rates $\tau_{\delta}$ and $\tau_{w}$ then give the government budget constraint

$$
\tau_{\delta} \delta \tilde{s}+\tau_{w} w \ell=\tau .
$$

To continue, we define the aggregate state of the world $\epsilon{ }^{11}$ The state of the world contains the exogenous technology $\triangle=(p, q, z, \omega)$ given by the energy cost $p$, investmentspecific productivity $q$, labor efficiency $z$, and the portion of energy for households $\omega$. The state of the world is further comprised of economy-wide energy, the total amounts of stocks firms hold, and aggregate equity shares, $\epsilon=(e, \mathrm{k}, \mathrm{x}, \mathrm{u}, \mathrm{s}, \triangle)$. The endogenous aggregate

\footnotetext{
${ }^{11}$ Equilibrium is compactly presented in a recursive way as in Greenwood, Hercowitz, and Krusell (1997).
} 
state evolves as $\left(e^{\prime}, \mathrm{k}^{\prime}, \mathrm{x}^{\prime}, \mathrm{u}^{\prime}, \mathrm{s}^{\prime}\right)=\Phi(\epsilon) \equiv(E(\epsilon), K(\epsilon), X(\epsilon), U(\epsilon), S(\epsilon))$, given the functions $E(\epsilon), K(\epsilon), X(\epsilon), U(\epsilon)$, and $S(\epsilon)$. Households and firms take expectations with respect to the evolution of the exogenous technology included in the motion of the state.

A competitive equilibrium can now be defined.

The Decision Problem of Households. The goal of a representative household is to maximize the present discounted value of utility in solving the problem

$$
V(\tilde{s}, \epsilon)=\max _{c, \ell, \tilde{s}^{\prime}}\left\{U(c, 1-\ell)+\beta \mathbb{E}\left[V\left(\tilde{s}^{\prime}, \epsilon^{\prime}\right)\right]\right\}
$$

subject to (a) the budget constraint,

$$
c+p(e-\mathrm{u})+\Psi(\epsilon) \tilde{s}^{\prime}=\left[\Psi(\epsilon)+\left(1-\tau_{\delta}\right) D(\epsilon)\right] \tilde{s}+\left(1-\tau_{w}\right) W(\epsilon) \ell+T(\epsilon),
$$

and (b) the law of motion of the endogenous aggregate state $\left(e^{\prime}, \mathrm{k}^{\prime}, \mathrm{x}^{\prime}, \mathrm{u}^{\prime}, \mathrm{s}^{\prime}\right)=\Phi(\epsilon)$, taking as given the dividend $\delta=D(\epsilon)$, prices $\psi=\Psi(\epsilon), w=W(\epsilon)$, and the lump-sum payment $\tau=T(\epsilon)[\mathrm{P}(1)]$.

The Decision Problem of Firms. A representative firm on a unit interval seeks to maximize the present discounted value of profits by solving the problem

$$
\begin{aligned}
Q(k, x, u, \epsilon)=\max _{\left(i_{m}(v)\right), \tilde{\ell}, k^{\prime}, x^{\prime}, u^{\prime}} & \left\{G(k, x, z \tilde{\ell})-W(\epsilon) \tilde{\ell}-p u-\left[k^{\prime}-\left(1-\delta_{k}\right) k\right]\right. \\
& \left.-\int_{v} i_{m}(v) \mathrm{d} v+\mathbb{E}\left[\frac{\Psi(\epsilon)}{\Psi\left(\epsilon^{\prime}\right)+D\left(\epsilon^{\prime}\right)} Q\left(k^{\prime}, x^{\prime}, u^{\prime}, \epsilon^{\prime}\right)\right]\right\}
\end{aligned}
$$

subject to (a) the laws of motion of energy services and use (9) and (10), and (b) the law of motion of the endogenous aggregate state $\left(e^{\prime}, \mathrm{k}^{\prime}, \mathrm{x}^{\prime}, \mathrm{u}^{\prime}, \mathrm{s}^{\prime}\right)=\Phi(\epsilon)$, taking as given the wage rate $W(\epsilon)$ and the discount factor $\Psi(\epsilon) /\left[D\left(\epsilon^{\prime}\right)+\Psi\left(\epsilon^{\prime}\right)\right][\mathrm{P}(2)]$.

Definition of Equilibrium. An equilibrium is a set of allocation functions for aggregate quantities - stocks $E, K, X, U$, and $S$, and flows $C, D, I$, and $L$, and pricing and transfer functions $\Psi, W$, and $T$, and an aggregate law of motion for endogenous states $\Phi(\epsilon)$ such that:

(i) Households solve problem $\mathrm{P}(1)$, taking as given the aggregate state of the world $\epsilon$, the functions $D, \Psi, W, T$, and $\Phi(\epsilon)$, so that individual chosen quantities are $c=C(\epsilon)$, $\ell=L(\epsilon)$, and $\tilde{s}^{\prime}=S(\epsilon)=1$.

(ii) Firms solve problem $\mathrm{P}(2)$, taking as given the aggregate state of the world $\epsilon$, and the functions $D, \Psi, W$, and $\Phi(\epsilon)$, firms are equity-financed, $Q(k, x, u, \epsilon)=(\Psi[\epsilon]+$ $D[\epsilon]) \mathrm{s}$, and individual chosen quantities are $\left(i_{m}(v)\right)=I(\epsilon), \tilde{\ell}=L(\epsilon),\left(k^{\prime}, x^{\prime}, u^{\prime}\right)=$ $(K(\epsilon), X(\epsilon), U(\epsilon))$.

(iii) The resource constraint of the consumption good holds in every period, that is,

$$
c+\int i_{m}(v) \mathrm{d} v+i_{k}+p e=G(k, x, z \ell)
$$


where $e$ designates economy-wide energy use, $e^{\prime}=\mathrm{u}^{\prime} /(1-\omega)$,

$$
i_{k}=\mathrm{k}^{\prime}-\left(1-\delta_{k}\right) \mathrm{k},
$$

and investment $\left(i_{m}(v)\right)$ govern the motion of aggregate energy services and energy use by firms, $\mathrm{x}^{\prime}=\left(1-\delta_{m}\right) \mathrm{x}+\int\left[f(v) q i_{m}(v) / v\right] \mathrm{d} v, \mathrm{u}^{\prime}=\left(1-\delta_{m}\right) \mathrm{u}+\int\left[q i_{m}(v) / v\right] \mathrm{d} v$.

Notice that in our equilibrium definition we have omitted the government budget constraint as it follows from the household budget constraint, the resource constraint, and the asset balancing condition.

\section{Qualitative Analysis}

This section presents our qualitative analysis of the model mechanisms which can potentially lead to the energy efficiency paradox.

\section{A. Key Model Effects}

To reveal the forces of technological change onto rebound and savings of energy use in our model, we here analyze the effects of changes in technology — capital and energy cost - on energy efficiency, services, and use. ${ }^{12}$ We can write equilibrium conditions to determine energy efficiency and energy use (conditions from which these can be derived are in the Appendix A):

$$
\begin{aligned}
\frac{1}{\varepsilon q} \varphi^{(1-\varepsilon) / \varepsilon} & =\beta G_{2}(k, \varphi u, z \ell), \\
(1-\varepsilon) \frac{1}{\varepsilon q} \varphi^{1 / \varepsilon} & =\beta p,
\end{aligned}
$$

where $G_{2}$ denotes the marginal product of output with respect to energy services and we have used that $\varphi=f(v)$.

The equilibrium level of energy services (being the product of energy efficiency and use) is chosen such that the marginal cost equals the marginal benefit of energy services (left and right side in condition (12)). Similarly, the equilibrium level of energy use balances its marginal benefit and marginal cost (left and right side in condition (13)). It is easy to see that the capital price $(1 / q)$ and the energy cost $(p)$ influence conditions (12) and (13). We can derive the following results.

PROPOSITION 1 (a): An increase in investment-specific productivity $q$ or the energy cost $p$ increases energy efficiency $\varphi$.

An increase in productivity $(q)$ induces to build more capital, which requires to use more energy given energy efficiency. To balance the marginal benefit and cost of energy with

\footnotetext{
${ }^{12}$ For the sake of clarity, we consider here a steady state of a simplified setup of our model which assumes that (1) energy-using capital fully depreciates within one period $\left(\delta_{m}=1\right),(2)$ there occurs no use of and investment in nonenergy-using capital $\left(\gamma=i_{k}=0\right)$, of which there exist a fixed number of units $\left(\delta_{k}=0, k\right.$ constant), (3) labor supply is exogenously fixed (at a value between zero and one), and (4) taxes are absent $\left(\tau_{\delta}=\tau_{w}=0\right)$. In the steady state, the equity return rate equals $\left(\psi^{\prime}+\delta^{\prime}\right) / \psi=1 / \beta$. In Section III.B and III.C, we consider growth in the full model.
} 
increased investment-specific productivity, the energy efficiency $(\varphi)$ must increase given greater energy efficiency raises the marginal benefit of energy. An increase in the energy cost $(p)$ raises the marginal cost of energy so that the marginal benefit of energy needs to increase which is achieved with greater energy efficiency $(\varphi)$ given that producing a fixed level of energy services requires less energy with higher energy efficiency. Unsurprisingly, adopting a neoclassical view, the capital-energy ratio depends positively on the relative price of energy to capital.

We conclude from Proposition 1(a) that lower capital cost and higher energy cost are energy-saving technological changes.

PROPOSITION 1 (b): An increase in investment-specific productivity $q$ (energy cost $p$ ) raises (lowers) energy services and use $x$ and $u$.

Consider the effects technology has on energy use. An increase in productivity $(q)$ has the direct effect of lowering the marginal cost of energy services as a given level of energy services requires fewer capital units given energy efficiency. It also has the indirect effects of lowering the marginal benefit and raising the marginal cost through increasing the energy efficiency. If the direct effect dominates, then the marginal benefit must decrease through an increase in energy use $(u)$. The direct effect dominates, if the marginal product of energy services is inelastic and energy efficiency is isoelastic, as the specification here assumes. ${ }^{13}$ An increase in the energy cost $(p)$, through increasing energy efficiency, lowers the marginal benefit and raises the marginal cost of energy services. To restore equality of marginal benefit and cost, energy use $(u)$ must decrease.

Consider now the effects of technology on energy services. These effects are analogous to the effects on energy use, because an increase in investment-specific productivity $(q)$ raises energy efficiency and enhances energy use. Clearly, this implies an increase in energy services $(x)$. An increase in the energy cost $(p)$, through increasing energy efficiency, raises the marginal cost of energy services. With diminishing returns to energy services, energy services $(x)$ must decrease. To summarize, with strict concavity in the setup, higher energy cost lowers energy use - a negative own-price effect, and in addition with isoelastic $f$ and $G$, lower capital cost increases energy use - a negative cross-price effect. Energy services respond as energy use does.

Proposition 1(b) thus establishes an ambiguous overall effect of energy-saving technological change - in the form of lower capital cost and higher energy cost - on energy use, meaning no bias for or against the energy efficiency paradox.

\section{B. Characterizing Long-Run Growth}

As a prerequisite to examine the role of induced energy efficiency for energy use in the long run, we now analyze features of a deterministic steady-state equilibrium path.

Change in Energy Use, Efficiency, and Services.-We first derive the change in energy use, energy efficiency, and energy services over time. The resource constraint (8) dictates that consumption, investment, and output grow at the same factor, or gross rate, denoted

\footnotetext{
${ }^{13}$ The proof of Proposition 1(b) in the Appendix A deploys general functional forms for production, and then uses the specification adopted above which enables balanced growth.
} 
by $g$. Investment-specific technological change expressed by

$$
\gamma_{q}=\text { gross rate of change in } q,
$$

then implies that aggregate energy-using capital $\int m(v) \mathrm{d} v$ grows at the rate $g \gamma_{q}$. Constant energy expenditure $p e / y$ shows that, with constant portion of household energy use $\omega$, energy use $(1-\omega) e$ is proportional to the ratio of output and energy price. The growth factor of energy use thus equals $g \gamma_{1 / p}$ with

$$
\gamma_{1 / p}=\text { inverse of gross rate of change in } p .
$$

We now derive the change in the capital intensity of energy and energy services important for our analysis of rebound and savings. As investment occurs in exactly one type of the capital intensity of energy at each date, using that it occurs in at most one type at a given date (see Lemma A.1 in the Appendix A) and that investment occurs along a balanced growth path, the type of new vintages $(v)$ changes at the rate capital relative to energy changes - equal to the ratio of the growth rate of investment-specific technology and the inverse of the rate of change in the energy price: $\gamma_{q} / \gamma_{1 / p}$. The growth factor of new vintage energy efficiency then reads $\left(\gamma_{q} / \gamma_{1 / p}\right)^{\varepsilon}$. That average energy efficiency $x / u$ changes at the same rate we confirm below and state here for convenience. The law of motion of services (9) then implies that energy services $x$ change at the gross rate $g \gamma_{q}{ }^{\varepsilon} \gamma_{1 / p}{ }^{1-\varepsilon} \cdot{ }^{14}$

We need to derive the change of market output to express services change solely in terms of technological change. Inserting the growth factor of nonenergy-using capital, $g$, and services yields a condition on the growth factor of labor efficiency $z$ - that is, $\gamma_{z}$ :

$$
g=\gamma_{z}\left[\gamma_{q}^{a \varepsilon} \gamma_{1 / p}^{a(1-\varepsilon)}\right]
$$

where $a \equiv \alpha(1-\gamma) /(1-\alpha)$ denotes the long-run elasticity of output with respect to average energy efficiency. ${ }^{15}$

Technological Gap.-We now show growth of average energy efficiency using necessary conditions for an equilibrium. We state necessary conditions for solutions to the households' and firms' problems $\mathrm{P}(1)$ and $\mathrm{P}(2)$, which we derived from conditions given in Appendix A.

The deterministic balanced growth path analogues to the Euler equations of energy services and energy use are

$$
\gamma_{q}=\left(\left[1-\tau_{\delta}\right] /\left[R-\tau_{\delta} g\right]\right)\left\{\alpha \varepsilon(1-\gamma)[\underbrace{\left(\frac{q^{\prime} y^{\prime}}{x^{\prime}}\right) \frac{f(v)}{v}}_{\phi^{\prime}}]+\left(1-\delta_{m}\right)\left(\gamma_{q} / \gamma_{1 / p}\right)^{1-\varepsilon}\right\}
$$

\footnotetext{
${ }^{14}$ To describe effects on energy use, we use that along a balanced growth path, technologies change at constant factors, $\gamma_{1 / p}=\gamma_{1 / p^{\prime}}, \gamma_{q}=\gamma_{q^{\prime}}$, and $\gamma_{z}=\gamma_{z^{\prime}}$, given $1 / \gamma_{1 / p^{\prime}} \equiv p^{\prime} / p, \gamma_{q^{\prime}} \equiv q^{\prime} / q$, and $\gamma_{z^{\prime}} \equiv z^{\prime} / z$.

${ }^{15}$ For each set of rates of change in the energy price $1 / \gamma_{1} / p$ and investment-specific productivity $\gamma_{q}$, and market output $g$, there exists a rate of labor efficiency change $\gamma_{z}$ consistent with a deterministic balanced growth path.
} 


$$
\gamma_{q}=\left(\left[1-\tau_{\delta}\right] /\left[R-\tau_{\delta} g\right]\right)\left\{\frac{\varepsilon}{1-\varepsilon}[\underbrace{\left(\frac{q^{\prime} y^{\prime}}{u^{\prime}}\right) \frac{1}{v}}_{\theta^{\prime}}](p u / y)+\left(1-\delta_{m}\right)\left(\gamma_{q} / \gamma_{1 / p}\right)\right\} .
$$

Entering these conditions is the steady-state value of the after-tax gross rate of return on equity $R^{\prime} \equiv\left[\psi^{\prime}+\left(1-\tau_{\delta}\right) \delta^{\prime}\right] / \psi$. The laws of motion of the corresponding stocks (9) and (10) can be rewritten as

$$
\begin{gathered}
\int\left[i_{m}(v) / y\right] \mathrm{d} v=\left[g \gamma_{q}-\left(1-\delta_{m}\right)\left(\gamma_{q} / \gamma_{1 / p}\right)^{1-\varepsilon}\right] / \phi, \\
\int\left[i_{m}(v) / y\right] \mathrm{d} v=\left[g \gamma_{q}-\left(1-\delta_{m}\right)\left(\gamma_{q} / \gamma_{1 / p}\right)\right] / \theta
\end{gathered}
$$

with the capital intensity of energy chosen by firms $v .^{16}$

We can now show that new and average energy efficiency have the same growth factor by interpreting $\phi$ and $\theta$. Along a balanced growth path, the capital intensity of energy of new capital $(v)$ and the capital-energy ratio $\left(\int m(v) \mathrm{d} v / u\right)$ grow at the same factor. That the measures grow at the same factor implies the interesting feature of a constant technological gap between energy efficiency in the youngest vintages of capital and average practice. Hence, new and average energy efficiency have the same growth factor.

To provide more detail, the technological gap can be expressed as the ratio $f(v) /\left(x^{\prime} / u^{\prime}\right)$ using energy services $x^{\prime}$ and energy use $u^{\prime}$ one period after $v$ was chosen. With steady values for $\phi$ and $\theta$, the gap factor equals $\phi / \theta$. Both $\phi$ and $\theta$ express quality-adjusted output-capital ratios, $\phi$ based on the average-to-new capital-service ratio and $\theta$ based on the average-to-new capital-energy ratio. ${ }^{17}$

We defer the necessary equilibrium conditions confirming constant labor supply, investmentto-output ratios, and the energy expenditure share to Section IV.B.

\footnotetext{
${ }^{16}$ The Euler equations and laws of motion with respect to energy services and energy use are written in terms of next period's energy-using capital. For example, a declining service yield of capital, $\left.\left[f\left(v^{\prime}\right) / v^{\prime}\right)\right] /[f(v) / v]=\left(\gamma_{1 / p} / \gamma_{q}\right)^{1-\varepsilon}<$ 1 , implies an upward adjustment of the depreciation factor in (15) and (17) - by stimulating the marginal cost of energy services. For example, a declining energy requirement, $\left[1 / v^{\prime}\right] /[1 / v]=\gamma_{1 / p} / \gamma_{q}<1$, leads to an upward adjustment of the depreciation factor in (16) and (18) - by stimulating the marginal benefit of energy use.

${ }^{17}$ The output-capital ratio times the ratio of the new to average capital-service ratio $\phi^{\prime}=\left(q^{\prime} y^{\prime} / \int m^{\prime}(v) \mathrm{d} v\right) \times$ $\left(\int m^{\prime}(v) \mathrm{d} v / x^{\prime}\right) /(v / f(v))$, is constant, $\phi=\phi^{\prime}$, where capital corresponds to energy-using capital. Likewise, the output-capital ratio times the relative capital-energy ratio $\theta^{\prime}=\left(q^{\prime} y^{\prime} / \int m^{\prime}(v) \mathrm{d} v\right) \times\left(\int m^{\prime}(v) \mathrm{d} v / u^{\prime}\right) / v$, is constant, $\theta=\theta^{\prime}$. New vintages' and average capital-service ratios change at the same rate, as do new vintages' and average capital-energy ratios. As the output-capital ratio $q y / \int m(v) \mathrm{d} v$ is constant, $\phi$ and $\theta$ each equal the output-capital ratio times a constant. Trivially, full depreciation of energy-using capital implies a technologigal gap factor of unity. That can be seen from the laws of motions of energy services and use (9) and (10).
} 


\section{Long-Run Change in Energy Use}

We now examine how energy use responds to factors that influence energy efficiency focusing on balanced growth. We provide the link between the growth representation and the basic idea of the model helpful to track the impact of technology on energy use.

Energy-Saving and Neutral Technological Change.-Let us first examine the channels through which technological change affects energy use over time. Investment-specific technological change (denoted by $\gamma_{q}=q^{\prime} / q$ ), the energy cost change (denoted by $1 / \gamma_{1 / p}=p^{\prime} / p$ ), and Harrod-neutral technological change (denoted by $\gamma_{z}=z^{\prime} / z$ ) affect the change in energy use, as can be seen in the growth factor of energy use

$$
\gamma_{1 / p} g=\left(\frac{p^{\prime}}{p}\right)^{-1}\left(\frac{p^{\prime}}{p}\right)^{-(1-\varepsilon) a}\left(\frac{q^{\prime}}{q}\right)^{\varepsilon a}\left(\frac{z^{\prime}}{z}\right)
$$

We learn from (19) the following effects on energy growth when comparing balanced growth paths. Lower cost for energy-using capital over time, $\gamma_{q}>1$, magnifies energy growth - the cross-price effect, as the construction of new investment goods requires output produced with investment goods at diminishing returns, using an insight from the key model effects presented in Section III.A. Moreover, higher cost for energy over time, $\gamma_{1 / p}<$ 1, suppresses energy growth - the own price effect. The own-price effect is direct through the energy expenditure, as the marginal benefit of energy is proportional to the outputenergy ratio thanks to isoelastic production of output from energy services (see Equation (16)), and indirect as an energy services effect, as energy efficiency is strictly concave in the capital intensity of energy (expressed by $\gamma_{1 / p}$ and $\left.\gamma_{1 / p}{ }^{(1-\varepsilon) a}\right)$. In addition, we note that neutral technological progress, $\gamma_{z}>1$, positively impacts energy growth. ${ }^{18}$

Utilizing the Basic Idea.- - Let us now examine the role of technological change for energy rebound and savings. Rebound relative to savings, both as defined in (2), can only be settled by disentangling the impact of energy-saving and neutral technological changes on energy growth. The growth factor of energy use when neutral technological change was absent reads $\tilde{g} \equiv \gamma_{1 / p} g / \gamma_{z}$. This growth factor can be expressed as

$$
\tilde{g}=\gamma_{1 / p} \gamma_{1 / p}^{a(1-\varepsilon)} \gamma_{q}^{a \varepsilon} .
$$

Recognizing the growth factor of energy use $\tilde{g} \gamma_{z}$ then disentangles the change of energy use into effects from energy-saving technological change, $\tilde{g}$, and neutral technological change, $\gamma_{z}$.

With a focus on balanced growth, we are interested in decomposing the change in energy use over time between an equilibrium with energy efficiency change (that is, a balanced growth path that, in an empirical application, brings the model close to the data, and an

${ }^{18}$ We find the decomposition of energy growth in (19) intuitive. Another representation of energy growth disentangles the overall impact of the energy cost into an input reallocation effect and an energy efficiency effect,

$$
\gamma_{1 / p} g=\left(\frac{p^{\prime}}{p}\right)^{-\frac{(1-\alpha \gamma)}{1-\alpha}}\left(\frac{p^{\prime}}{p}\right)^{\varepsilon a}\left(\frac{q^{\prime}}{q}\right)^{\varepsilon a}\left(\frac{z^{\prime}}{z}\right) .
$$

Accordingly, higher energy cost decreases energy use through input reallocation and increases energy use through greater energy efficiency. 
equilibrium with no energy efficiency change (that is, another balanced growth path. To reflect the sources of energy efficiency change, the paths are characterized by empirical and no energy-saving technological change. For the purpose of this section we define the gross rate of change in energy efficiency $\gamma_{\varphi} \equiv\left(\gamma_{q} / \gamma_{1 / p}\right)^{\varepsilon}$.

Using equations (2) and (14), the change in energy services and energy efficiency $\vartheta_{E}$ and $\eta_{E}$ can be written in terms of technological changes so that ${ }^{19}$

$$
r=\left(\tilde{g}-\frac{1}{\gamma_{\varphi}}\right) \gamma_{z}, \quad s=\left(1-\frac{1}{\gamma_{\varphi}}\right) \gamma_{z}
$$

We control for neutral technological change by keeping it constant, thus keeping $\gamma_{z}>0$ constant. Thus, while the magnitudes of rebound and savings depend on neutral technological change, the ratio of rebound to savings is unaffected by neutral technological change. The growth factor $\tilde{g}$ (defined above) contains the capital price effect, or cross-price effect, on energy use $\left(\gamma_{q}^{a \varepsilon}\right)$ and the energy price effect, or own-price effect, on energy use (comprised of $\gamma_{1 / p}$ and $\left.\gamma_{1 / p}{ }^{a(1-\varepsilon)}\right)$. The energy cost constitutes a technology, not a market price of energy. Thus, the energy cost does not adjust to counterfactual changes, rather the energy cost characterizes counterfactual changes.

Equipped with our model and focusing on balanced growth, we can thus derive (with technological change altering energy efficiency in observations):

PROPOSITION 2: Rebound and savings of energy use, given by (20), have the properties:

(i) Savings are positive, $s>0$, if technological change improves energy efficiency over time, $\gamma_{\varphi}>1$.

(ii) Savings are negative, $s<0$, if technological change depresses energy efficiency over time, $\gamma_{\varphi}<1$.

(iii) Rebound is positive, $r>0$, if technological change stimulates energy services (so that energy services relative to output expand), $\tilde{g}>1 / \gamma_{\varphi}$.

(iv) Rebound is negative, $r<0$, if technological change slows energy services (so that energy services relative to output contract), $\tilde{g}<1 / \gamma_{\varphi}$.

(v) Rebound exceeds savings, $r>s$, if and only if technological change increases energy use, $\tilde{g}>1$.

Proposition 2 can be used to show that the model can predict energy savings, and may or may not include the energy efficiency paradox depending on the values for parameters.

The Energy Efficiency Effect on Energy Use. Intuitively, energy savings occur whenever energy efficiency in the observed equilibrium improves over time. The response of energy

\footnotetext{
${ }^{19}$ Specifically, denoting the equilibrium with and with no energy efficiency change by 1 and $0, \eta_{1}=\gamma_{\varphi}, \eta_{0}=1$, $\vartheta_{1}=\gamma_{\varphi} \tilde{g} \gamma_{z}$, and $\vartheta_{0}=\gamma_{z}$. Along a path with observed rates of technological change, we can decompose the change in energy use, that is, $\tilde{g} \gamma_{z}=\gamma_{\varphi}^{-1} \gamma_{\varphi} \tilde{g} \gamma_{z}$, where $\gamma_{\varphi} \tilde{g} \gamma_{z}$ represents the growth factor of energy services. Note that for the counterfactual equilibrium with no energy-saving technological change, we have used 1 in place of $\gamma_{q}$ and $\gamma_{1 / p}$ (rather than introduce new symbols, we let $\gamma_{q}$ and $\gamma_{1 / p}$ equal their observed values, which $\tilde{g}$ and $\gamma_{\varphi}$ use).
} 
use to energy efficiency is captured by the sign of $\left(1-\gamma_{\varphi}{ }^{-1}\right)$, which measures the difference in the average rate of change in energy use between energy efficiency change based on the counterfactual rate of energy-saving technological change (1) and the observed rate $\left(\gamma_{\varphi}{ }^{-1}\right)$. The model, by predicting improved energy efficiency in the long run (through the values for the parameters $\gamma_{q}$ and $\gamma_{1 / p}$ ), can thus contain positive energy savings, $\gamma_{\varphi}>1$.

The Energy Efficiency Paradox Can Hold. Given positive energy savings, positive (negative) energy rebound counteracts (reinforces) energy savings. Suggested by the definition of rebound, the sign of the rebound depends on the response of energy services to energysaving technological change. Rebound is positive, if energy-saving technological change stimulates energy services, and negative, if energy-saving technological change slows energy services. The response of energy use to energy services change is captured by the sign of $\left(\tilde{g}-\gamma_{\varphi}{ }^{-1}\right)$, which measures the difference in the average rate of change in energy use between energy services change based on observed rates of energy-saving technological change $(\tilde{g})$ and counterfactual rates $\left(\gamma_{\varphi}{ }^{-1}\right)$. The energy efficiency paradox emerges necessarily with lower capital and energy cost over time $\left(\gamma_{q}>\gamma_{1 / p}>1\right)$, as both these technological changes enhance energy use. Then on an observed equilibrium path energy use increases because of energy-saving technological change, $\tilde{g}>1$. The increase of energy services induced by lower capital cost over time can also overcompensate the decrease in energy services induced by higher energy cost over time $\left(\gamma_{q}>1>\gamma_{1 / p}\right)$ so that on an observed equilibrium path energy use increases because of energy-saving technological change, $\tilde{g}>1$. Then rebound exceeds savings, $r>s .^{20}$

The Energy Efficiency Paradox Can Fail. We need to keep in mind that, using (20), an increase in the rate of change of investment-specific productivity (greater $\gamma_{q}$ ) raises rebound and savings, while an increase in the rate of change of energy cost (smaller $\gamma_{1 / p}$ ) lowers rebound and raises savings. The model thereby allows for backfire of energy consumption to energy-saving technological change $(0<s<r)$, conservation of energy $(0<r<s)$ and super conservation of energy $(r<0<s)$.

Importantly, energy-saving technological change in the form of a declining capital price and an increasing energy cost over time $\left(\gamma_{1 / p}<1<\gamma_{q}\right)$ can affect energy use, hence energy rebound relative to savings, ambiguously.

COROLLARY 1: With a declining capital cost $(1 / q)$ and an increasing energy cost $p$, an increase in energy efficiency ambiguously affects rebound relative to savings, $r$ smaller than, equal to, or greater than $s$.

\section{The Implicit Price for Energy Services}

Before we turn to the empirical application, we now discuss how the implicit price for energy services relates to the case when rebound exceeds savings, or the energy efficiency paradox.

The implicit price for energy services equal to the marginal product of energy services $(\alpha(1-\gamma) y / x)$ declines over time if energy services relative to output expand. Thus, a declining price for energy services appears equivalent to positive energy rebound, as that is

\footnotetext{
${ }^{20}$ The efficiency paradox, $r>s$, also obtains trivially with energy-dissaving technological change implying negative savings (in one case, necessarily if $\gamma_{1 / p}>\gamma_{q}>1$, and in another case, but not necessarily, if $\gamma_{q}<1<\gamma_{1 / p}$ ).
} 
equivalent to an increase in energy efficiency $(x / u)$ relative to energy cost $(p), \gamma_{\varphi}>1 / \gamma_{1 / p}$. Notice that the growth factor of energy efficiency relative to energy cost can be stated as $\gamma_{1 / p} \gamma_{\varphi}=\left\{\tilde{g} \gamma_{\varphi}\right\}^{1 /(1+a)}$.

For example, consider the directions of technological change suggested in the introduction. An energy cost increase over time $\left(\gamma_{1 / p}<1\right)$ lowers the implicit price for energy services dynamically by raising energy efficiency. But energy services also become more expensive in terms of consumption because of the direct effect of energy cost on energy expenditure, which dominates the two effects. Investment-specific technological progress $\left(\gamma_{q}>1\right)$ suppresses the implicit price for energy services by raising energy efficiency. The progress can be large enough to achieve a positive rebound by overcompensating the effect of higher energy cost on the implicit price for energy services, thus leading to a decline in the implicit price, but may yield rebound not large enough to exceed savings. As a result, with induced energy efficiency increase $\left(\gamma_{\varphi}>1\right)$, the paradox that rebound exceeds savings implies a decline in the implicit price, but not reversely.

\section{Matching the Model with Observables}

This section describes our procedure to match model and data yielding parameter values enabling to obtain quantitative results. We also describe the data used to construct variables, and how we used moments in the data.

\section{A. The Data}

We give here a brief overview of the data sources and the main issues involved in constructing our dataset. Appendix B provides more detail. To construct values for variables, we use annual time series data for the U.S. economy 1960-2011. ${ }^{21}$ Energy use and energy deflators are constructed from the Energy Information Administration's AER-Annual Energy Review 2011 (EIA, 2014a) and SEDS - State Energy Data System 1960-2012 (EIA, 2014b). ${ }^{22}$ We construct a composite measure for energy from consumption of coal, oil, natural gas, and biomass, and of electricity. The series for coal, oil, natural gas, and biomass are net of use for electricity generation. To construct a common deflator, we use the deflators of and expenditures on nondurable consumption goods and services from the NIPA - National Income and Product Accounts (BEA, 2014b). To measure investmentspecific technology, we use NIPA deflators for equipment investment and structures investment. To measure investment, we use the NIPA expenditures on private nonresidential equipment and structures investment. ${ }^{23}$ To construct a variable for market output, we use

\footnotetext{
${ }^{21}$ Energy price data are only available from 1960 thus determining the first year of our sample. Using hours worked until 2011 determines the last year of the sample.

${ }^{22}$ The current releases of the energy data used are available at http://www.eia.gov/totalenergy/data/annual/ and http://www.eia.gov/state/seds/seds-data-complete.cfm.

${ }^{23}$ We think that this is a good measurement of energy-using and non-energy-using capital. Buildings comprise the majority of structures value in the data as measured in the NIPA of the BEA, while other components are pipelines, railroad tracks, and electricity transmission lines. Minor components of structures are heating and cooling systems that are sold together with building frames. It is thus a good approximation to measure our non-energyusing capital in the model by structures in the data. Similarly, the BEA identifies equipment capital largely with mobile devices, thus expressing our understanding of energy-using capital. We acknowledge, however, that both measures for equipment and structures in the data are not perfect. For example, a small part of the BEA measure for equipment capital contains some non-energy-using capital such as furniture.
} 
NIPA gross domestic product, imports, exports, and the owner-occupied housing value. To measure capital stock, we use net stock of fixed assets from the FAA-Fixed Asset Accounts (BEA, 2014a). ${ }^{24}$ In particular, we utilize energy-sector expenditures on investment and capital stock to adjust corresponding aggregate series for the treatment of energy expenditure in the model. To inform the investment-specific shift in technology in energy-using capital, we extend Gordon's (1990) equipment investment deflator 1947-1983 until 2011 using an aggregative approach which incorporates the NIPA equipment investment deflator relative to a common deflator in the NIPA. To gauge labor supply, we use the available time for work and hours worked by the noninstitutional population aged 16-64 given by Cociuba, Prescott, and Ueberfeldt (2012). By measuring quantity variables relative to the number of hours, we control for population growth.

\section{B. Calibration}

To continue, we need to find values for twelve parameters: $\beta$ and $\xi$ determining preferences, $\alpha, \gamma, \varepsilon, \gamma_{q}$ and $\gamma_{1 / p}$ governing production, $\delta_{m}$ and $\delta_{k}$ for depreciation of capital, $\omega$ for the relative energy use, and $\tau_{\delta}$ and $\tau_{w}$ representing government policy. All parameter values are found from data targets without the need to simulate the model. A time period is taken to be one year.

We first provide further necessary conditions for equilibrium that we use to fit the model to the data. The deterministic balanced growth path analogue to the Euler equation of nonenergy-using capital stock and a representation of the law of motion of the stock (7) are

$$
\begin{gathered}
1=\left(\left[1-\tau_{\delta}\right] /\left[R-\tau_{\delta} g\right]\right)\left\{\alpha \gamma(y / k)+1-\delta_{k}\right\}, \\
i_{k} / y=\left[g-\left(1-\delta_{k}\right)\right] /(y / k) .
\end{gathered}
$$

Remaining are conditions for the choices of consumption and equity holdings by households, the allocation of time to work and leisure from $\mathrm{P}(1)$ and $\mathrm{P}(2)$, and the use of market output along a balanced growth path (confirming constant labor supply, investment-tooutput ratios, and the energy expenditure share):

$$
\begin{gathered}
R=g / \beta, \\
\left(1-\tau_{w}\right)(1-\alpha)[(1-\ell) / \ell]=[(1-\xi) / \xi] c / y, \\
c / y+\int\left[i_{m}(v) / y\right] \mathrm{d} v+i_{k} / y+p e / y=1, \\
(p u / y)=(1-\omega)(p e / y) .
\end{gathered}
$$

${ }^{24}$ The national account data used are taken from http://www.bea.gov/iTable/index.cfm. 
Equation (23) combines the necessary conditions for the choice of consumption and equity holdings by households. Equation (24) governs households' use of time using the marginal rate of substitution between consumption and leisure $U_{2} / U_{1}=[(1-\xi) / \xi] c /(1-\ell)$, as well as the necessary condition for the firms' choice of labor input equating the wage rate to the marginal product of labor in the market. Here the marginal utility of consumption $U_{i}$ denotes the derivative of $U$ with respect to its $i$ th argument. The resource constraint (stated in the equilibrium condition [iii]) can be rewritten as (25).

The following moments in the data are targeted to directly yield parameter values: (i) $D e-$ preciation rates for capital, M1 and M2. Interpreting energy-using capital as private nonresidential equipment, we set $\delta_{m}$ equal to the depreciation rate for equipment capital in the data, 13.9 percent. ${ }^{25}$ We measure nonenergy-using capital used in the market as private nonresidential structures. Analogous to the procedure for the depreciation rate for equipment capital, we find the depreciation rate for structures capital of 3.9 percent. We take this value for $\delta_{k}$. (ii) Long-run change in equipment productivity, M3. The deflator for consumption relative to the deflator for equipment investment has steadily increased, at 3.1 percent on average per year, as reported in Appendix B, giving $\gamma_{q}$. (iii) Long-run change in output-energy ratio, $M 4$. The output-energy ratio increased on average per year by 0.5 percent. ${ }^{26}$ As energy expenditure relative to market output $p u / y$ stays constant along a balanced growth path, we can determine the inverse of the long-run change in the energy price, $\gamma_{1 / p}$. (iv) Labor share of income, M5. The labor share of income often found is 0.7 , while in the model equals $(1-\alpha)$, which can be used to solve for $\alpha$. Different methods yield different estimates for the labor share of income. We thus explore other values for $\alpha$ in Section VI.B. (v) Labor income tax rate, M6. The marginal tax rate on labor in the model is $\tau_{w}$. We use the estimate from Lucas (1990), namely 0.4. We thus infer the following parameter values directly from the moments M1-M6:

\begin{tabular}{lcccccc}
\hline Parameter & $\delta_{m}$ & $\delta_{k}$ & $\gamma_{q}$ & $\gamma_{1 / p}$ & $\alpha$ & $\tau_{w}$ \\
Value & 0.139 & 0.039 & 1.031 & 0.995 & 0.3 & 0.4 \\
\hline
\end{tabular}

The values for the remaining parameter values are obtained consistent with behavior by households and firms in equilibrium targeting the following moments in the data: (i) Longrun change in output, M\%. Real gross national product (GNP) less the owner-occupied housing value per hour available for work on average has grown by about 1.3 percent per year $(g=1.013)$. (ii) Investment-output ratios, M8 and M9. The mean of investment relative to GNP (net of gross housing product) is 7.0 percent related to nonresidential equipment and 3.1 percent to structures $\left(\int i_{m}(v) \mathrm{d} v / y=0.070\right.$ and $\left.i_{k} / y=0.031\right)$. (iii) $I n$ terest rate, $M 10$. The mean after-tax return on capital was four percent $(R=1.04) .{ }^{27}$

\footnotetext{
${ }^{25}$ We use the sample mean of $\left[1-\left(\tilde{m}^{\prime}-\tilde{q} \int i_{m}(v) \mathrm{d} v\right) / \tilde{m}\right]$ with measured real stock $\tilde{m}$, investment-specific technology $\tilde{q}$, and real investment $\int i_{m}(v) \mathrm{d} v$. To obtain a series for $\tilde{m}$ and $\int i_{m}(v) \mathrm{d} v$, the current-cost private nonresidential equipment capital stock in the data we divide by the one-period lagged deflator for investment goods and hours and the current-cost private nonresidential equipment investment we divide by the common deflator and hours. See Appendix B for the reason behind this procedure. For the investment-specific technology $\tilde{q}$, we use the ratio of common deflator to NIPA investment goods deflator.

${ }^{26}$ Energy use on average has increased by 0.8 percent per year. Together with the output growth rate of 1.3 percent (both per available hour for work), this yields an average annual increase in the output-energy ratio of 0.5 percent.

${ }^{27}$ McGrattan and Prescott (2003) report the NIPA 1929-2008 mean return on capital of 4 percent. This estimate
} 
(iv) Fraction of time worked, M11. The total working hours on average represent the fraction 0.236 of available time for work $(\ell=0.236) .{ }^{28}$ (v) Energy expenditure, M12 and M13. Energy expenditure by businesses relative to the value of market goods given by GNP (net of owner-occupied housing product) has been on average 3.4 percent $(p u / y=0.034)$. Relative economy-wide energy expenditure has been on average 6.1 percent $(p e / y=0.061)$. Using these moments, we solve a system of ten equations, consisting of (15)-(18) and (21)(26), for ten parameters and stationary values of endogenous economic variables that we have not targeted:

\begin{tabular}{lcccccc}
\hline Parameter & $\gamma$ & $\varepsilon$ & $\beta$ & $\xi$ & $\omega$ & $\tau_{\delta}$ \\
Value & 0.44 & 0.81 & 0.97 & 0.30 & 0.44 & 0.84 \\
\hline
\end{tabular}

and $(c / y)=0.84,(y / k)=1.68, \phi=2.54$, and $\theta=2.11$. The reason for the fact that we have used one moment more than we obtained values for parameters is that Equation (14) delivers the growth factor of the Harrod-neutral technology $\gamma_{z}=1.0072$.

To validate growth accounting, the balanced growth of the Harrod-neutral technology should be similar to the growth of the Harrod-neutral technology that one can compute as a residual (using model and data). The Harrod-neutral technology residual we computed as described in the Online Appendix, similar to $\gamma_{z}$, grew on average on the sample period with a factor of 1.0071 .

We have calibrated our model to output and energy growth on average in the data. The equilibrium balanced growth path reflecting observed average growth thus depicts the average behavior of energy efficiency, energy services, and energy use over the sample period. ${ }^{29}$

\section{Quantitative Results}

This section presents our quantitative results on the energy efficiency paradox, and more generally, the role of technological change for long-run energy use, based on the calibrated model.

\section{A. Increased Energy Efficiency, Higher Energy Use?}

We can now show that rebound of energy use has overcompensated savings of energy use in response to technological change. Table 1 shows the terms giving rebound and savings as average annual rates of change, which we now interpret.

is close to the quarterly U.S. data 1954-2008 annual mean after-tax return on private capital of 3.93 in Gomme, Ravikumar, and Rupert (2011) and the annual U.S. data 1959-1996 mean after-tax return on capital for the nonfinancial corporate sector of 3.9 percent in Poterba (1998). The balanced growth path after-tax return on equity is held equal to the observed mean after-tax return on capital. McGrattan and Prescott (2003) report the U.S. data 1880-2002 mean after-tax return on equity of 5.4 percent. They argue that it is an upper bound, because their calculation excludes "capital-gains taxes, brokerage costs, and possibly higher pre-1980 diversification costs" than accounted for (McGrattan and Prescott, 2003, 394).

${ }^{28}$ We use data on population size and total working hours from the Bureau of Labor Statistics as provided in Cociuba, Prescott, and Ueberfeldt (2012).

${ }^{29}$ Nontargeted moments in the data are matched well. The output-capital ratio $(y / k)$ and quality-adjusted outputcapital ratio $\left(q y / \int m(v) \mathrm{d} v\right)$ have a mean in the data and on the model balanced growth path equal to 1.68 and mean in the data and model of 2.66 and 2.62. These good fits imply that rebound and savings, derived with targeting the ratios of investment to output, are robust to targeting the ratios of output to capital. The balanced growth path value for $\left(q y / \int m(v) \mathrm{d} v\right)$ can be derived as $\left[g \gamma_{q}-\left(1-\delta_{m}\right)\right] /\left(\int i_{m}(v) \mathrm{d} v / y\right)$. 
TABLE 1

REBOUND AND SAVINGS OF ENERGY USE

\begin{tabular}{lc}
\hline \hline Rebound $(100 \times r)$ & $2.92(=0.79+2.13)$ \\
With effect of energy-saving technological & 0.79 \\
change on energy services $\left[100\left(\tilde{g} \gamma_{z}-1\right)\right]$ & -2.13 \\
Without effect of energy-saving technological & \\
change on energy services $\left[100\left(\gamma_{\varphi}^{-1} \gamma_{z}-1\right]\right)$ & $2.85(=0.72+2.13)$ \\
Savings $(100 \times s)$ & 0.72 \\
$\quad$ Without effect of energy-saving technological & -2.13 \\
change on energy efficiency $\left[100\left(\gamma_{z}-1\right)\right]$ & \\
$\quad \begin{array}{l}\text { With effect of energy-saving technological } \\
\text { change on energy efficiency }\left[100\left(\gamma_{\varphi}^{-1} \gamma_{z}-1\right)\right]\end{array}$ & 1.02 \\
Rebound rate $(r / s)$ &
\end{tabular}

Notes: Values shown refer to average annual percentage change of energy use. Calculations are based on equation (20) using $\gamma_{\varphi}=\left(\gamma_{q} / \gamma_{1 / p}\right)^{\varepsilon}$ and $\tilde{g}=$ $g \gamma_{1 / p} / \gamma_{z}$ evaluated at energy-saving technological change, output growth, capital elasticity of energy services, and neutral technology growth derived from the calibration of the model $\left(\gamma_{q}=1.031\right.$ and $\gamma_{1 / p}=0.995$, and $g=$ 1.013, $\varepsilon=0.81$, and $\gamma_{z}=1.0072$, implying that $\left.\tilde{g}=1.0007\right)$.

Focusing first on energy savings, the calibrated model reveals an increase in energy efficiency $\left(\gamma_{\varphi}>1\right)$, thus identifies positive energy savings, $s>0$. Energy use (expressed per hour available for work) would have increased by 0.72 percent per year in the absence of energy-saving technological change and given neutral technological change (with no effect from energy efficiency). Energy use would have declined by 2.13 percent per year with the energy efficiency improvements as identified by our model, if one controls for the impact of energy-saving technological change on energy service demand (with effect from energy efficiency). The energy savings from energy efficiency improvements $(s)$ are thus 2.85 percent per year. This confirms the energy savings hypothesis which states that energy efficiency improvements bring about reductions in energy use.

Reporting now energy rebound, calculating a decline in energy use based on an increase in energy efficiency was correct when energy services do not move (with no effect from energy services). But the energy services cannot be held fixed. The energy savings are counteracted by greater energy use required from rising energy services following energysaving technological change, leading to positive rebound, $r>0$. Energy use had grown by 0.79 percent per year with this effect from energy services, controlling for the effect of energy efficiency on energy use (with effect from energy services), leading to an energy rebound from energy services' response of 2.92 percent per year in the economy.

We thus find evidence for energy rebound in excess of energy savings with an economywide rebound rate $r / s$ of 1.02 . It seems unsurprising that the rebound rate is positive but the striking result is that the rebound rate is much closer to one than to zero; in fact it is greater than one. Energy demanded thus "backfired" in response to energy-saving technological change: higher energy efficiency has increased, not reduced energy use - thus providing a confirmation of the energy efficiency paradox.

\section{B. The Role of Energy-saving Technological Change for Long-Run Growth of Energy}

As noted in Proposition 2, rebound exceeds savings if energy use increases because of energy-saving technological change. To see why this holds in our sample, it is instructive to investigate the different channels through which energy-saving technological change affects 
energy use.

By way of (19), energy use has experienced a relatively strong cross-price effect from investment-specific technological change that has dominated the negative own-price effect, direct and indirect, following higher energy prices. We find that the relative contribution of each of these three effects to the growth in energy use (had neutral technological change been absent) using equilibrium growth accounting was: 822 percent for the cross-price effect, -31 percent for the indirect own-price effect, and -691 percent for the direct ownprice effect. The following reasons thus emerge for an energy rebound rate in excess of one: (1) A strong decline in the equipment capital price relative to the energy price, as depicted by Figure 1B. (2) A sufficiently high elasticity of growth in output with respect to growth in energy services. ${ }^{30}$ If energy services comprised only a small income share of output $(\alpha(1-\gamma))$, then intuitively the effect on energy use induced by energy-saving technological change would be much smaller, in turn implying a lower rebound rate.

Our numerical result that the energy rebound rate is larger than one is robust with respect to changing $\varepsilon$ - the capital elasticity of vintage energy services. This can be seen as follows. Using our empirical value for $\tilde{g}$, which expresses the growth factor of energy use relative to the growth factor of labor productivity, and any growth in the capital-energy ratio $\left(\gamma_{q} / \gamma_{1 / p}>1\right)$, it follows from equation (20) that with a change in $\varepsilon$ the rebound still exceeds savings.

Higher energy efficiency thus increased rather than reduced energy use, because investmentspecific technological progress enhanced energy use by more than the increase in the energy price reduced it.

\section{Sources for Long-Run Growth of Energy}

We now examine the relative importance of energy-saving and neutral technological change for the observed growth in energy use through equilibrium growth accounting.

Table 2 summarizes the contribution of different technological changes to long-run energy growth as identified by measurement of our model. Both neutral and investment-specific technological changes were major determinants of observed growth in energy use. In detail, energy use per available working hour would have decreased on average by 0.54 percent per year if the nonresidential equipment price and Harrod-neutral technology had been constant in the long run. This number corresponds to the joint impact of the two effects of the energy cost on energy demand in (19). Energy use would have increased by 0.60 percent if the energy cost and Harrod-neutral technology had been constant. This number corresponds to the effect of the equipment capital cost on energy demand in (19). Energy use would have grown by 0.69 percent if the nonresidential equipment and energy prices had been constant. This number corresponds to the effect of the Harrod-neutral technology on energy demand in (19). Equipment-specific technological change thus contributed about 80 percent to energy-per-hour growth $[=0.60 /(0.60-0.54+0.69)]$. Higher energy prices contributed about -72 percent to energy-per-hour growth $[=-0.54 /(0.60-0.54+0.69)]$. The remaining contribution by Harrod-neutral technological change with 92 percent is the

\footnotetext{
${ }^{30}$ The cross-price effect from investment-specific technological change is magnified if output change is relatively elastic with respect to services change, which is expressed by the exponent $a=\alpha(1-\gamma) /(1-\alpha)$. We derive $a=0.24$. Importantly, this "large" value reflects the importance of energy services relative to other factors (labor and structures capital) in production.
} 


\begin{tabular}{lcc}
\hline \hline & \multicolumn{2}{c}{$\begin{array}{c}\text { Contribution } \\
\text { to growth of energy use } \\
\text { (in percent) }\end{array}$} \\
\cline { 2 - 3 } & $\begin{array}{c}\text { Absent } \\
\text { neutral } \\
\text { technological } \\
\text { change }\end{array}$ & $\begin{array}{c}\text { With } \\
\text { technoutral } \\
\text { change }\end{array}$ \\
Technological Change & 822 & 80 \\
\hline $\begin{array}{l}\text { Equipment-specific technological change } \\
\text { Energy price change }\end{array}$ & -31 & -72 \\
$\quad \begin{array}{l}\text { Indirect } \\
\text { Direct }\end{array}$ & -691 & 92 \\
\hline Harrod-neutral technological change & & 92 \\
\hline
\end{tabular}

Notes: The growth accounting uses equation (19).

relatively most important source for growth in energy use.

Importantly, we can see that energy use would have grown if only energy-saving technological change had occurred, because the effect of equipment-specific technological change outweighed the combined effects of the energy cost change on energy demanded. This relates the overall growth accounting here to the accounting of the role of energy-saving technological change for energy use in the Section V.B.

\section{Extensions and Robustness Checks}

This section extends the model to household production to separately assess the energy efficiency paradox for energy used in the market and in the households and reports on a number of robustness checks. In addition, this section reports on introducing alternative counterfactual viewpoints.

\section{A. Household Production}

To assess energy rebound and savings separately for market and household energy use requires chosen household energy use. Given a symmetric production structure in both sectors and the plausible assumption of energy production using market output, any difference in these sectors' rebound and savings will accrue from differences in investment-specific technological change and the production function of energy services across these sectors. The details of the model extension are in the Online Appendix. We here present the expressions for rebound and savings comparing balanced growth paths and describe our results.

Let $\vartheta_{E, i}$ and $\eta_{E, i}$ denote the gross rate of change in energy services and energy efficiency in equilibrium $E \in\{0,1\}$ and sector $i \in\{M, N\}$. We then have:

$$
r_{i}=\left(\tilde{g}-\frac{1}{\gamma_{\varphi_{i}}}\right) \gamma_{z_{M}}, \quad s_{i}=\left(1-\frac{1}{\gamma_{\varphi_{i}}}\right) \gamma_{z_{M}}
$$

using the change in energy efficiency $\gamma_{\varphi_{i}} \equiv\left(\gamma_{q_{i}} / \gamma_{1 / p}\right)^{\varepsilon_{i}}$ for $i \in\{M, N\} .{ }^{31}$ The gross rate of

$$
{ }^{31} \text { Specifically, } \eta_{1, i}=\gamma_{\varphi_{i}}, \eta_{0, i}=1, \vartheta_{1, i}=\gamma_{\varphi_{i}} \tilde{g} \gamma_{z_{M}} \text {, and } \vartheta_{0, i}=\gamma_{z_{M}} \text {. We have used } \tilde{g} \gamma_{z_{M}}=\left(\gamma_{\varphi_{i}}\right)^{-1} \gamma_{\varphi_{i}} \tilde{g} \gamma_{z_{M}} \text {. }
$$


change $\tilde{g}$ is relevant for energy services change in both the household and market sectors as it appears in the change of energy services $\vartheta_{1, i}$ for both sectors. This reflects that energy used by both firms and households is paid for with market output.

We can now quantify rebound and savings of household energy use in the long run. For comparison, we here report results for the market and household sectors. We define the rebound rate $\rho_{i}$ as the ratio of rebound to savings by sector $i \in\{M, N\}$ through evaluating $(27)$,

$$
\rho_{i} \equiv r_{i} \times \frac{1}{s_{i}}
$$

Focusing first on energy savings, business and household energy use would have increased by 0.72 percent per year in the absence of energy-saving technological change and given neutral technological change (with no effect from energy efficiency). Business (household) energy use would have declined by 2.13 (2.18) percent per year with the energy efficiency improvements as identified by our model, if one controls for the impact of energy-saving technological change on energy service demand (with effect from energy efficiency). The energy savings $s_{i}$ from energy efficiency improvements for business (household) energy use are thus 2.85 (2.90) percent per year. This confirms the energy savings hypothesis which states that energy efficiency improvements bring about reductions in energy use.

Reporting now energy rebound, the energy savings are counteracted by greater energy use required from the increase in energy services following energy-saving technological change. Business and household energy use had grown by 0.79 percent per year with this effect from energy services, controlling for the effect of energy efficiency on energy use (with effect from energy services), leading to an energy rebound $r_{i}$ from energy services' response of 2.92 (2.97) percent per year for businesses (households).

We thus find evidence for energy rebound in excess of energy savings with an economywide rebound rate of 1.02 by weighting $\rho_{M}=2.92 / 2.85$ for businesses and $\rho_{N}=2.97 / 2.90$ for households. ${ }^{32}$ Rebound and savings of energy use are similar in the two sectors because the household sector's investment-specific technological change and capital intensity of energy elasticity of energy efficiency $\left(\gamma_{q_{N}}=1.032\right.$ and $\left.\varepsilon_{N}=0.80\right)$ only slightly deviate from the market sector's corresponding parameters $\left(\gamma_{q_{M}}=1.031\right.$ and $\left.\varepsilon_{M}=0.81\right)$. It seems unsurprising that the sectoral rebound rates are positive but the striking result is that the rebound rates are much closer to one than to zero; in fact they are greater than one. We can thus confirm our earlier result, obtained with no chosen household energy use, that higher energy efficiency has increased, not reduced energy use - thus providing a confirmation of the energy efficiency paradox.

The accounting of contributions to growth of economy-wide energy use found in Sections V.B and V.C remains valid in this extension. Energy is paid in units of market output; hence effects appearing in the growth factor of economy-wide energy use are those from the market sector.

Note that for the counterfactual equilibrium with no energy-saving technological change $(E=0)$, we have used 1 in place of $\gamma_{q_{i}}$ and $\gamma_{1 / p}$ (rather than introduce new symbols, we let $\gamma_{q_{i}}$ and $\gamma_{1 / p}$ equal their calibrated values, which $\tilde{g}$ and $\gamma_{\varphi_{i}}$ use).

${ }^{32}$ An economy-wide rebound rate can be calculated as a weighted average of sectoral rebound rates $\rho_{M}$ and $\rho_{N}$. As the sectoral rebound rates turn out to be quite similar, the specific weighting scheme does not play a role for the value of the economy-wide rebound rate. 
TABLE 3

REBOUND AND SAVINGS OF ENERGY USE BY SECTOR

\begin{tabular}{lcc}
\hline \hline & $(i=M)$ & $(i=N)$ \\
\hline Rebound $\left(100 \times r_{i}\right)$ & $2.92(=0.79+2.13)$ & $2.97(=0.79+2.18)$ \\
$\quad$ With effect of energy-saving technological & 0.79 & 0.79 \\
change on energy services [100 $\left.\left(\tilde{g} \gamma_{z_{M}}-1\right)\right]$ & -2.13 & -2.18 \\
Without effect of energy-saving technological & & \\
change on energy services [100 $\left.\left(\gamma_{\varphi_{i}}{ }^{-1} \gamma_{z_{M}}-1\right)\right]$ & & $2.90(=0.72+2.18)$ \\
Savings $\left(100 \times s_{i}\right)$ & $2.85(=0.72+2.13)$ & 0.72 \\
$\quad$ Without effect of energy-saving technological & 0.72 & -2.18 \\
change on energy efficiency $\left[100\left(\gamma_{z_{M}}-1\right)\right]$ & -2.13 & 1.02 \\
With effect of energy-saving technological & & \\
change on energy efficiency $\left[100\left(\gamma_{\varphi_{i}}-1 \gamma_{z_{M}}-1\right)\right]$ & 1.02 & \\
Rebound rate $\left(r_{i} / s_{i}\right)$ &
\end{tabular}

Notes: Average annual percentage change of businesses and households energy use. Calculations are based on equation (27) using $\varphi_{M}=\left(\gamma_{q_{M}} / \gamma_{1 / p}\right)^{\varepsilon_{M}}, \varphi_{N}=\left(\gamma_{q_{N}} / \gamma_{1 / p}\right)^{\varepsilon_{N}}$, and $\tilde{g}=g \gamma_{1 / p} / \gamma_{z_{M}}$ evaluated with energy-saving technological change $\gamma_{q_{M}}=1.031, \gamma_{q_{N}}=1.032, \gamma_{1 / p}=0.995$, and $g=1.013, \varepsilon_{M}=0.81, \varepsilon_{N}=0.80$, and $\gamma_{z_{M}}=1.0072$ that are derived from the calibrated model, implying that $\tilde{g}=1.0007$.

\section{B. Robustness Checks}

This section discusses the role of several assumptions we have made for our estimation of the energy rebound rate: no exogenous trend in energy efficiency, full utilization of energy-using capital, interest rate target in the data, and estimation method for the labor share of income.

Exogenous Energy Efficiency Change.-The literature on energy rebound uses only autonomous, or exogenous, energy efficiency. We have assumed only induced, or endogenous, energy efficiency which helps to identify technological change altering energy efficiency. We here relate to the literature by qualitatively investigating the role of exogenously increasing energy efficiency for the energy efficiency paradox. We also consider an exogenous factor in the capital-energy ratio. Suppose that energy efficiency of type $\left(v^{A}, v\right)$ equals $f\left(v^{A} v\right)$, where $v^{A}$ evolves exogenously. One unit of capital of a given chosen type $v$ contributes the number of units of energy services $f\left(v^{A} v\right) / v^{B} v$, where $v^{B}$ exogenously affects the capitalenergy ratio $\left(v^{B} v\right)$. Energy services and energy use are then $x=\int \frac{1}{v^{B} v} m(v) f\left(v^{A} v\right) \mathrm{d} v$ and $u=\int \frac{1}{v^{B} v} m(v) \mathrm{d} v$. On a balanced growth path, an exogenous energy efficiency change appears through the constant growth factor of $v^{A}$, namely, $\Lambda$. Denoting the relative growth factor of $v^{A}$ to $v^{B}$ as $\Lambda_{0}$, one obtains the effects of newly introduced technology on energy services growth $\tilde{g}^{A}=\Lambda_{0}^{a \varepsilon}$ and on energy efficiency $\gamma_{\varphi}{ }^{A}=\Lambda_{0}{ }^{\varepsilon}$. The expressions for rebound and savings are then modified as

$$
r=\left(\tilde{g}^{A} \tilde{g}-\frac{1}{\gamma_{\varphi}^{A} \gamma_{\varphi}}\right) \gamma_{z}, \quad s=\left(1-\frac{1}{\gamma_{\varphi}^{A} \gamma_{\varphi}}\right) \gamma_{z} .
$$

With the same data, the introduction of the two neutral technologies $v^{A}$ and $v^{B}$ cause to adjust the value for the gross rate of Harrod-neutral technological change, $\gamma_{z}$. All other parameters, however, stay the same, because the extended model with autonomous energy 
efficiency improvement here appears observationally equivalent to the basic model. ${ }^{33}$ It appears reasonable to assume that the frontier of vintage-specific energy services given capital and energy input (given by the total factor productivity of variety-specific energy services $\left.\left(v^{A} / v^{B}\right)^{\varepsilon}\right)$ stays the same or shifts out, $\Lambda_{0} \geq 1$.

Now suppose there was an exogenous increase in energy efficiency (which cannot be identified with the data we use) in addition to technological change in producing energy-using capital and converting resources into energy. Chosen energy efficiency adjusts. Clearly, then rebound exceeded savings $\left(r>s\right.$ with $\left.\tilde{g}^{A} \tilde{g}-\left(\gamma_{\varphi}{ }^{A} \gamma_{\varphi}\right)^{-1}>1-\left(\gamma_{\varphi}{ }^{A} \gamma_{\varphi}\right)^{-1}>0\right)$. The rebound rate with both autonomous and induced changes to energy efficiency exceeds the rebound rate with only induced changes to energy efficiency we have analyzed so far (the rebound rate increases in $\Lambda_{0} \geq 1$ ). Thus, positing only capital and energy price changes to affect the long-run evolution of energy efficiency does not bias our assessment in which we have confirmed the efficiency paradox. ${ }^{34}$

Utilization of Capital.- Using a minimum (or, Leontief) production function for energy services, relatively old energy-using capital would be idle on a balanced growth path. An energy efficiency increase of young capital over time yields incentives to idle old capital with low energy efficiency on a balanced growth path. Assuming full utilization, however, simplifies the calibration of the depreciation of energy-using capital (with chosen utilization, the depreciation schedule for differently aged capital would need to be estimated) and, more importantly, enable to back out a neutral technology residual without knowing the utilization rate of capital on the sample period in the data. The technology residual is useful to check the validity of the model for growth accounting. With capital being used finitely long on a balanced growth path, the question would arise what utilization rate to apply to compute the residual on the sample period. Allowing to choose the utilization of capital could in principle affect the estimation of the energy rebound rate based on the calibrated model. We can gauge the effect of allowing to choose utilization without actually implementing it.

Assuming full utilization is a good approximation, if the scrapping age of capital is large. To gauge the scrapping age, for each vintage, we can check the economic incentive for underutilization given our calibrated model and residual energy services (that led to the neutral technology measure). For details, see the Online Appendix. ${ }^{35}$ We find that all capital units installed after 1976 would be fully utilized on the remainder of the sample period if utilization could be chosen. Equipment capital and durable goods depreciate so fast that only a small fraction of capital units would be underutilized - representing only up to a maximum of less than 0.1 percent for a given date over our sample period in both the

\footnotetext{
${ }^{33}$ The change in energy efficiency and services, $\left(\gamma_{q} / \gamma_{1 / p}\right)^{\varepsilon} \Lambda_{0}{ }^{\varepsilon}$ and $g\left(\Lambda_{0} \gamma_{q}\right)^{\varepsilon} \gamma_{1 / p}{ }^{1-\varepsilon}$, imply the growth factor of energy use as before $\gamma_{1 / p} g$. Now the growth factor of output giving $\gamma_{z}$ equals $g=\gamma_{z}\left[\left(\Lambda_{0} \gamma_{q}\right)^{a \varepsilon}\left(\gamma_{1 / p}\right)^{a(1-\varepsilon)}\right]$.

${ }^{34}$ Relatedly, Lemoine (2015) analyzes how energy production efficiency (the inverse of energy production cost, or energy cost) affects energy use. In particular, he focuses on increased energy production efficiency, thus lower energy cost, leading to higher energy use. He argues rebound overcompensates savings, but this is not trivial. With our concepts of rebound and savings, lower energy cost yields lower energy use efficiency, or energy efficiency, producing more energy services, and hence negative savings and positive rebound (see Proposition 2(ii) and (iii)), given capital and energy are substitutable factors. Note also that we use instead that the energy cost became higher in the long run to picture the empirical long-run movements both in energy use and GNP consistent with the trend of the relative price of energy.

${ }^{35}$ In contrast, for simulated models with a discrete number of capital goods which are mothballed, see Gilchrist and Williams (2000) and Wei (2013).
} 
market and household sector. Full utilization of capital is thus an innocuous assumption in our context.

Time Preference.- One may argue that market data do not reflect well time preference. We have inferred the time discount factor $(\beta)$ using data on the after-tax rate of return on capital. We now explore the rebound rate when reversing the procedure. The aftertax return rate $R$ becomes lower when households become more patient (higher $\beta$ ) given growth of market output (see Equation (23)). Thus, greater patience, through lowering the interest rate $R$, decreases the capital intensity elasticity of energy efficiency $\varepsilon_{N}$ (see Equation (O.16) in the Online Appendix), and thereby increases the rebound rate in the household sector, $\rho_{N}$. The value for $\beta$ does not affect the calibrated parameter values for market production, and thereby has no impact on the rebound rate in the market sector, $\rho_{M}$.

Changing the time discount factor to imply an after-tax interest rate of $R \in\{1.02,1.07\}$, lower and higher than the benchmark value taken from the data $(R=1.04)$, has only a negligible effect on the economy-wide energy rebound rate; in terms of the contour plot shown in Figure 2 there is virtually no difference. The effect is small because the elasticity of energy efficiency with respect to the capital-energy ratio calibrated as $\varepsilon_{N} \in\{0.79,0.82\}$ only slightly deviates from the benchmark case $\left(\varepsilon_{N}=0.80\right)$.

Labor Share of Income.- There are various methods to find the labor share of aggregate income in any given period by using national accounts data. In particular, according to Cooley and Prescott (1995), the labor share of income is upwardly biased with standard disaggregation of income flows in the NIPA. We thus here explore a labor share of income of 60 percent $(\alpha=0.4)$, implying $\gamma=0.48$. A labor share as low as 60 percent increases the energy rebound to 112 percent of energy savings (rebound-to-savings rate of 1.12), as the long-run elasticity of output with respect to average energy efficiency in the market, $a=\alpha(1-\gamma) /(1-\alpha)$, increases to 0.35 . With our benchmark value for the labor share of income of 70 percent $(\alpha=0.3)$, implying $\gamma=0.44$, we have thus erred optimistically for a low energy rebound relative to savings. The labor share of income is constant over time as we use a unitary elasticity of substitution production function (Cobb-Douglas) for market output. See Karabarbounis and Neiman (2014) for a transient labor share of income in a model brought about by a different value for the elasticity and being affected by the relative price of investment.

\section{Alternative Counterfactual Viewpoints}

This section introduces alternative viewpoints on the state of technology defining the counterfactual economy used to assess the energy efficiency paradox.

A more narrow view of the energy efficiency paradox would control for changes in the energy price. To implement this view, we now vary investment-specific technological change, controlling for the energy price change, by keeping the energy price change at its empirical level. In addition, we consider energy price rebound controlling for investment-specific technological change. Energy rebound and savings are calculated using the formula in (27) now based on new counterfactual changes of energy efficiency and services $\tilde{\eta}_{0, i}$ and $\tilde{\vartheta}_{0, i}$ that are determined by the rates of change of the inverse of the energy price $\left(\lambda_{1 / p}\right)$, and business equipment-specific technology $\left(\lambda_{q_{M}}\right)$, and durable goods-specific technology $\left(\lambda_{q_{N}}\right)$. To attain the economy-wide energy rebound rate $\rho$, the rebound rates of the market and 


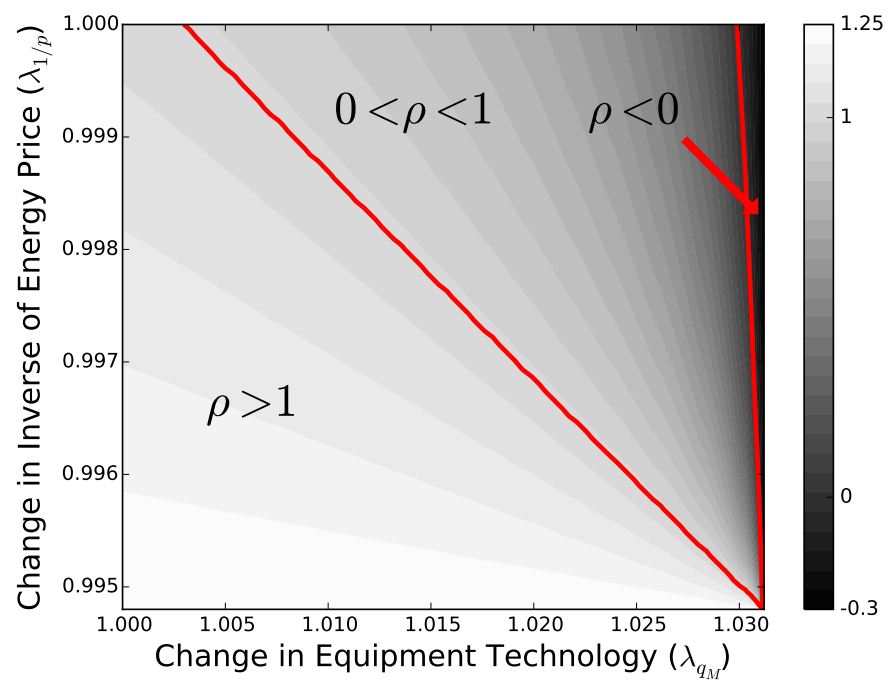

Fig 2. Energy Rebound Rate $\rho$ 1960-2011: Alternative Counterfactual Viewpoints about Energy-Saving Technological Change

Notes: The counterfactual average annual growth factor of equipment-specific technology is on the $x$-axis. The counterfactual average annual growth factor of the inverse in the energy price is on the $y$-axis. The counterfactual growth rates of equipment-specific technology $\left(\lambda_{q_{M}}, \lambda_{q_{N}}\right)$ are positively related through $\ln \lambda_{q_{N}}=\ln \lambda_{q_{M}} \ln \gamma_{q_{N}} / \ln \gamma_{q_{M}}$. The diagonal red curve shows cases for $\rho=1$; the red curve close to the right edge of the box shows cases for $\rho=0$.

household sectors are weighted with the mean of the empirical portion of sectoral energy on the sample period. ${ }^{36}$

The rebound rate to either source of energy-saving technological change is 1.25 (narrow view of the energy efficiency paradox) and -0.30 (energy price rebound). By construction, the rebound rate controlling for energy price change is larger than unity and the energy price rebound rate is smaller than zero. Despite the a priori known ranges for these rebound rates, the magnitudes are far less clear. On average over the period of the sample, for each percent potential savings of energy use, equipment-specific technological change has counteracted with a rebound of energy use of 1.25 percent (controlling for energy price change). In contrast, the energy price increase saved energy at the rate of -0.30 percent (controlling for investment-specific technological change). The positive rebound related to investment-embodied technological progress thus was much stronger than the negative rebound from higher energy prices.

The two cases analyzed above represent counterfactual cases controlling for one type of energy-saving technological change by holding it at its empirical value. These cases bound the three-dimensional space of counterfactual technology for capital price change in each sector and energy price change. The space is spanned by the values corresponding to no change (the respective gross rate of change equal one) and empirical rates of change. Figure

${ }^{36}$ The respective expressions for energy efficiency and services change for $E=0$ are then given by $\tilde{\eta}_{0, i}=$ $\left(\lambda_{q_{i}} / \lambda_{1 / p}\right)^{\varepsilon_{i}}$ and $\tilde{\vartheta}_{0, i}=\left(\lambda_{q_{i}} / \lambda_{1 / p}\right)^{\varepsilon_{i}} \lambda_{1 / p} \gamma_{z_{M}}\left[\lambda_{q_{M}}{ }^{\varepsilon_{M}} \lambda_{1 / p}{ }^{a\left(1-\varepsilon_{M}\right)}\right]$. The rebound rate controlling for energy price change can be obtained for $\lambda_{1 / p}=\gamma_{1 / p}, \lambda_{q_{M}}=1, \lambda_{q_{N}}=1$. The rebound relative to the energy savings controlling for capital price change uses $\lambda_{1 / p}=1, \lambda_{q_{M}}=\gamma_{q_{M}}, \lambda_{q_{N}}=\gamma_{q_{N}}$. 
2 shows the contour set of the economy-wide energy rebound rate $\rho$ on a two-dimensional subspace of this space as an example. To attain this subspace, we fix a positive relationship between sectoral technological changes specific to investment in energy-using capital. It contains the point of empirical rates of changes for investment-specific technological and energy price change at the bottom-right corner. The bottom-left corner depicts the case of the narrow view of the energy efficiency paradox when controlling for energy price change, the top-right corner depicts the case of the energy price rebound when investmentspecific technological change is held at the empirical value. Note that the axes show the counterfactual rates of changes.

Figure 2 bears out the following insights (for the chosen example fixing a positive relationship between sectoral investment-specific technological changes). First, the economy-wide rebound rate will be the larger (smaller) the farther away the counterfactual rate of change of investment-specific technology (energy price) lies from its empirical value. ${ }^{37}$ Second, the variation in the distance between the contour levels of the rebound rate implies that the rebound rate increases more than proportionally when moving the counterfactual rate of change away from the empirical value for the equipment-specific technology. The effect from equipment-specific technological progress thus turns out to be increasingly important as counterfactual and empirical values for this type of energy-saving technological change are more distant from one another. This underlines the importance of considering changes in income through energy-saving technological progress.

Importantly, Figure 2 makes clear that the size of the rebound rate depends on the design of the counterfactual of energy-saving technological change. Each design of the counterfactual case yields a distinct rebound rate which needs to be interpreted accordingly, even though different designs can yield the same value of the rebound rate. The case relevant to the energy efficiency paradox, or energy rebound hypothesis, that greater energy efficiency leads to greater energy use - in line with the conjecture by Jevons (1865) involves no energy-saving technological change which is depicted in the top-left corner exhibiting an energy rebound rate in excess of one.

\section{Conclusion}

A fundamental question in economics is whether improvements in resource efficiency lead to a reduction in the use of the resource. This question, for example, prominently arises in the context of fossil energy resources and climate change mitigation: will an everincreasing energy efficiency induced by technological advances help to lower the use of fossil fuels or will resource use respond positively to technological advances as economic prosperity increases?

In this paper, we have examined the response of energy use to technological change. To conceptually and empirically examine the energy efficiency paradox - that with increased energy efficiency, energy use increases - we have developed a model with technology-induced energy efficiency identifying rebound and savings of energy use through changes in capital and energy costs. We demonstrate that the energy efficiency paradox encapsulates the role of factors leading to changes in the efficiency of energy in producing energy services. The

\footnotetext{
${ }^{37}$ The maximum and minimum rebound rates are reached with controlling for energy price change and for capital price change separately.
} 
size of the energy rebound relative to the energy savings is influenced by factors determining the cost of energy. A higher energy cost leads to greater energy efficiency and smaller energy use whereas a lower energy cost implies smaller energy efficiency and greater energy use. Our finding that equipment-specific and energy cost changes over time have led rebound to exceed savings of energy use in the U.S. economy over the 1960-2011 period on average per year provides evidence supporting the energy efficiency paradox. This casts strong doubts on the view that energy-saving technological change lowered fossil energy use - and has thus contributed to addressing the challenges of fossil fuels related to climate change, local pollution, and energy security.

In this paper, we have investigated technology-induced energy efficiency improvements. An important direction for future research is to analyze how chosen energy efficiency responds to government policies aimed at reducing energy use. Moreover, we have assumed that consumers are completely informed about the costs and benefits when making decisions about resource use. It would thus be interesting to extend our analysis of energy rebound to include alternative behavioral paradigms involving, for example, consumer internalities such as the underestimation of energy savings in the context of durable consumption goods and equipment. More generally, our framework could also be applied to study the challenges to sustainability of other resources - such as water, rare materials, or the capacity to absorb waste - that are essential for economic well-being.

\section{References}

Acemoglu, D., P. Aghion, L. Bursztyn, and D. Hemous (2012): "The environment and directed technical change," American Economic Review, 102, 131-166.

Acemoglu, D., U. Akcigit, D. Hanley, and W. Kerr (2016): "Transition to clean energy," Journal of Political Economy, 124, 52-104.

Aghion, P., A. Dechezleprêtre, D. Hémous, R. Martin, and J. Van Reenen (2016): "Carbon taxes, path dependency, and directed technical change: Evidence from the auto industry," Journal of Political Economy, 124, 1-51.

Atkeson, A., and P. J. Kehoe (1999): "Models of energy use: Putty-putty versus puttyclay," American Economic Review, 89, 1028-1043.

BEA (U.S. Bureau of Economic Analysis) (2014a): "Fixed Asset Accounts," Accessed online September 9, 2014.

$$
13,2014 .
$$

(2014b): "National Income and Product Accounts," Accessed online September

Binswanger, M. (2001): "Technological progress and sustainable development: What about the rebound effect?," Ecological Economics, 36, 119-132.

Borenstein, S. (2015): "A microeconomic framework for evaluating energy efficiency rebound and some implications," The Energy Journal, 36(1), 1-21.

Brookes, L. G. (1990): "The greenhouse effect: The fallacies in the energy efficiency solution," Energy Policy, 18(2), 199-201.

Cociuba, S. E., E. C. Prescott, and A. Ueberfeldt (2012): "U.S. Hours and Productivity Behavior Using CPS Hours Worked Data: 1947-III to 2011-IV," Mimeograph.

Cooley, T. F., and E. C. Prescott (1995): "Economic Growth and Business Cycles," in Frontiers of Business Cycle Research, ed. by T. F. Cooley, pp. 1-38. Princeton University Press, Princeton. 
Cummins, J. G., and G. L. Violante (2002): "Investment-specific technical change in the United States (1947-2000): Measurement and macroeconomic consequences," Review of Economic Dynamics, 5, 243-284.

Davis, L. W., A. Fuchs, and P. Gertler (2014): "Cash for coolers: Evaluating a large-scale appliance replacement program in Mexico," American Economic Journal: Economic Policy, 6, 207-238.

Díaz, A., and L. Puch (2013): "A Theory of Vintage Capital Investment and Energy Use," UC3M Working paper 13-20, Universidad Carlos III de Madrid.

EiA (Energy Information Administration) (2014a): "Annual Energy Review 2011," Accessed online June 19, 2014.

2015.

(2014b): "State Energy Data System 1960-2012," Accessed online January 13,

Fowlie, M., M. Greenstone, and C. Wolfram (2018): "Do energy efficiency investments deliver? Evidence from the Weatherization Assistance Program," Quarterly Journal of Economics, 133, 1597-1644.

Gilchrist, S., and J. Williams (1998): "Investment, Capacity, and Output: A PuttyClay Approach," Manuscript, Washington: Bd. Governors, Fed. Reserve System.

- (2000): "Putty-clay and investment: A business cycle analysis," Journal of Political Economy, 108, 928-960.

Gillingham, K., D. S. Rapson, and G. Wagner (2016): "The Rebound Effect and Energy Efficiency Policy," Review of Environmental Economics and Policy, 10, 68-88.

Gomme, P., B. Ravikumar, and P. Rupert (2011): "The return to capital and the business cycle," Review of Economic Dynamics, 14, 262-278.

Gordon, R. J. (1990): The Measurement of Durable Goods Prices. University of Chicago Press, Chicago.

Gort, M., J. Greenwood, and P. Rupert (1999): "Measuring the rate of technological progress in structures," Review of Economic Dynamics, 2, 207-230.

Greening, L. A., D. L. Greene, and C. Difiglio (2000): "Energy efficiency and consumption - the rebound effect - a survey," Energy Policy, 28, 389-401.

Greenwood, J., and Z. Hercowitz (1991): "The allocation of capital and time over the business cycle," Journal of Political Economy, 99, 1188-1214.

Greenwood, J., Z. Hercowitz, and P. Krusell (1997): "Long-run implications of investment-specific technological change," American Economic Review, 87, 342-362.

Hassler, J., P. Krusell, and C. Olovsson (2012): "Energy-Saving Technical Change," NBER Working Paper 18456.

Jacobsen, M. R., and A. A. VAn Benthem (2015): "Vehicle scrappage and gasoline policy," American Economic Review, 105, 1312-1338.

Jevons, W. (1865): The Coal Question. Macmillan and Co., London.

Karabarbounis, L., and B. Neiman (2014): "The global decline in the labor share of income," Quarterly Journal of Economics, 129, 61-103.

Khazzoom, D. J. (1980): "Implications of mandated efficiency in standards for household appliances," The Energy Journal, 1(4), 21-40.

Knittel, C. R. (2011): "Automobiles on steroids: Product attribute trade-offs and technological progress in the automobile sector," American Economic Review, 101(7), 33683399. 
Krusell, P., L. Ohanian, J. Ríos-Rull, and G. L. Violante (2000): "Capital-skill complementarity and inequality: A macroeconomic analysis," Econometrica, 68, 10291053.

Lemoine, D. (2015): "General Equilibrium Rebound from Energy Efficiency Policies," Mimeograph.

Levinson, A. (2016): "How much energy do building energy codes save? Evidence from California houses," American Economic Review, 106, 2867-2894.

LuCAS, R. E. (1990): "Supply-side economics: An analytical review," Oxford Economic Papers, 42, 293-316.

McGrattan, E. R., and E. C. Prescott (2003): "Average debt and equity returns: Puzzling?," American Economic Review, 93, 392-397.

Michaels, R. J. (2012): "Energy Efficiency and Climate Policy: The Rebound Dilemma," Institute for Energy Research, Report.

Newell, R. G., A. B. Jaffe, and R. N. Stavins (1999): "The induced innovation hypothesis and energy-saving technological change," Quarterly Journal of Economics, 114(3), 941-975.

Nordhaus, W. D. (1996): "Do real-output and real-wage measures capture reality? The history of lighting suggests not," in The Economics of New Goods, ed. by T. F. Bresnahan, and R. J. Gordon, pp. 27-70. University of Chicago Press (for NBER), Chicago.

PAKKo, M. R. (2002): "What happens when the technology growth trend changes? Transition dynamics, capital growth, and the "New Economy"," Review of Economic Dynamics, 5, 367-407.

Popp, D. (2002): "Induced innovation and energy prices," American Economic Review, 92(1), $160-180$.

Poterba, J. (1998): "Rate of return to corporate capital and factor shares: New estimates using revised national income accounts and capital stock data," Carnegie-Rochester Conference Series on Public Policy, 48, 211-246.

Saunders, H. D. (1992): "The Khazzoom-Brookes postulate and neoclassical growth," Energy Journal, 13, 131-148.

Steinbuks, J., and K. Neuhoff (2014): "Assessing energy price induced improvements in efficiency of capital in OECD manufacturing industries," Journal of Environmental Economics and Management, 68, 340-356.

Thomas, B. A., and I. L. Azevedo (2013): "Estimating direct and indirect rebound effects for U.S. households with input-output analysis Part 1: Theoretical framework," Ecological Economics, 86, 199-210.

WEI, C. (2003): "Energy, the stock market, and the putty-clay investment model," American Economic Review, 93, 311-323.

(2013): "A dynamic general equilibrium model of driving, gasoline use and vehicle fuel efficiency," Review of Economic Dynamics, 16, 650 - 667.

WEI, T. (2007): "Impact of energy efficiency gains on output and energy use with CobbDouglas production function," Energy Policy, 35, 2023 - 2030. 


\section{Appendix A: Equilibrium Behavior and Proofs}

This appendix provides first-order necessary conditions for an equilibrium and proofs characterizing equilibrium.

\section{Lemma}

We use for characterizing equilibrium the result that firms choose a unique type of energyusing capital in every period provided the current capital stock is not too large (because of irreversible investment, for a too large capital stock there would be no investment). This was proven in Atkeson and Kehoe (1999) in a putty-clay model with no investment-specific technological change. We thus present the result in a model with such change here:

LEMMA A.1: Investment occurs in at most one type of energy-using capital $v \in(0, \infty)$ in every period.

Proof. Suppose that $i_{m}(v)>0$ some $v \in(0, \infty)$. Then two conditions must be met, $q f \mu_{x}-q \mu_{u}=v$ and $\left[f-f_{1} v\right] \mu_{x}=\mu_{u}$, using the nonnegative Lagrange multipliers $\mu_{x}$ on (9) and $\mu_{u}$ on (10). It remains to be shown that $i_{m}\left(v^{\prime}\right)=0$ all $v^{\prime} \neq v$. Combining the conditions yields that $q \mu_{x}=1 / f_{1}$ and $q \mu_{u}=\left[f-f_{1} v\right] / f_{1}$. The first equation delivers $\mu_{x}>0$ since $f_{1}(v)>0$. As $\mu_{x}$ is unique and $f_{1}$ strictly decreases in $v$, the desired result follows. (A similar argument can be developed from $\mu_{u}$. Suppose that $\mu_{u}=0$, which is to be contradicted. The second equation shows $f-f_{1} v=0$, but $f>f_{1} v$, by strict concavity of $f$. Thus, $\mu_{u}>0$. As $\mu_{u}$ is unique and the term $\left[f-f_{1} v\right] / f_{1}$ strictly increases in $v$, by strict concavity of $f>0$, the desired result follows.) QED

The result is implied by the strict concavity of the energy efficiency in the capital-energy ratio analogous to Atkeson and Kehoe (1999). It must be noted that uniqueness of the marginally profitable type of energy-using capital does not restrict the growth factor of energy efficiency on a balanced growth path. One could introduce a convexity or allow for multiple energy services and obtain investment in multiple types with the same growth factor.

\section{Equilibrium Behavior in Section II}

We find conditions governing investment and the capital intensity of energy of new investment goods. We then utilize these conditions to express the Euler equations.

The proof of Lemma A.1 shows that investment in energy-using capital $i_{m}(v)>0$ and the chosen capital intensity of energy $v$ imply the marginal benefit of energy services $\mu_{x}=1 / q f_{1}$ and the marginal cost of energy use $\mu_{u}=\left[f-f_{1} v\right] / q f_{1}$, equal to the Lagrange multipliers on (9) and (10).

The allocation rules for $c, k^{\prime}, x^{\prime}, u^{\prime}, \ell$, and $\delta$, and pricing rule for $\psi$, in an equilibrium are implicit functions in the following system of equations. The Euler equations associated with the stocks of nonenergy-using capital, energy services, and energy used by firms are:

$$
1=\mathbb{E}\left[\frac{\psi}{\psi^{\prime}+\delta^{\prime}}\left(G_{1}\left(k^{\prime}, x^{\prime}, z^{\prime} \ell^{\prime}\right)+1-\delta_{k}\right)\right]
$$




$$
\begin{gathered}
\frac{1}{q f_{1}(v)}=\mathbb{E}\left[\frac{\psi}{\psi^{\prime}+\delta^{\prime}}\left(G_{2}\left(k^{\prime}, x^{\prime}, z^{\prime} \ell^{\prime}\right)+\left(1-\delta_{m}\right) \frac{1}{q^{\prime} f_{1}\left(v^{\prime}\right)}\right)\right] \\
\frac{f(v)-f_{1}(v) v}{q f_{1}(v)}=\mathbb{E}\left[\frac{\psi}{\psi^{\prime}+\delta^{\prime}}\left(p^{\prime}+\left(1-\delta_{m}\right) \frac{f\left(v^{\prime}\right)-f_{1}\left(v^{\prime}\right) v^{\prime}}{q^{\prime} f_{1}\left(v^{\prime}\right)}\right)\right]
\end{gathered}
$$

where $v$ and $v^{\prime}$ denote the capital intensity of energy of energy-using capital chosen by firms. The Euler equation associated with the holdings of equity shares by households can be stated as:

$$
\psi U_{1}(c, 1-\ell)=\beta \mathbb{E}\left[\left(\psi^{\prime}+\left(1-\tau_{\delta}\right) \delta^{\prime}\right) U_{1}\left(c^{\prime}, 1-\ell^{\prime}\right)\right] .
$$

The efficiency condition of labor demand and supply is

$$
z\left(1-\tau_{w}\right) G_{3}(k, x, z \ell)=\frac{U_{2}(c, 1-\ell)}{U_{1}(c, 1-\ell)} .
$$

Together with the asset balancing condition (given in the equilibrium condition [ii]), the resource constraint (given in the equilibrium condition [iii] evaluated at $e=u /(1-\omega)$ ), and the laws of motion (7), (9), and (10), as well as the equations (A1)-(A5) define the allocation rules.

The conditions from $\mathrm{P}(1)$ determine households' stocks of nonenergy-using capital, services from energy-using capital and energy use, and the financial asset, in addition to the use of time given dividends $d$ and the wage rate $w$. The conditions from $\mathrm{P}(2)$ equate the wage rate to the marginal product of time directed to market production and leave the firm with profits to pay for investments, and pay out dividends.

\section{Proof of Proposition 1}

Part a: We need to show (12) and (13) (where $\varphi=f(v)$ thanks to full depreciation of energy-using capital). Because of the interiority shown in Lemma O.1 (see Online Appendix), the conditions (O.1) and (O.2), or, assuming an interior solution, the firstorder conditions with respect to energy services and use $x$ and $u$ (A2) and (A3), can be written as

$$
\begin{aligned}
\frac{1}{q f_{1}(v)} & =\beta F_{1}(x), \\
\frac{f(v)-f_{1}(v) v}{q f_{1}(v)} & =\beta p .
\end{aligned}
$$

This uses $F(x) \equiv G(k, x, z \ell)$ at constant $k$ and $z \ell$. Now we can use the uniqueness established in Lemma O.1. Consider the effects $q$ and $p$ have on energy efficiency $f(v)$. 
An increase in $q$ lowers the left side, and an increase in $p$ raises the right side, in (A7). To restore equality, the capital intensity of energy $v$, and so the energy efficiency $f(v)$, must increase.

Part b: Consider the effect $q$ has on energy use $u$. Totally differentiating (A6) yields

$$
\begin{gathered}
\left\{\beta F_{11}(x) f(v)\right\} \mathrm{d} u=[\underbrace{\left\{-\beta F_{11}(x) f_{1}(v) u\right\}}_{(+)}+\underbrace{\left\{-f_{11}(v) /\left(q\left[f_{1}(v)\right]^{2}\right)\right\}}_{(+)}] \mathrm{d} v \\
+\{\underbrace{-1 /\left[q^{2} f_{1}(v)\right]}_{(-)}\} \mathrm{d} q .
\end{gathered}
$$

An increase in investment-specific productivity $(q)$ has the direct effect of lowering the marginal cost of energy services given capital intensity of energy (the outmost right term in braces). It also has the indirect effects of lowering the marginal benefit and raising the marginal cost through increasing the capital intensity of energy (the first and second term in braces on the right side). The total differential of (A7) implies that the capital intensity of energy increases with investment-specific productivity $(\mathrm{d} v / \mathrm{d} q>0)$ as used above for $\mathrm{d} p=0$,

$$
0=\left\{-f(v) f_{11}(v) / f_{1}(v)\right\} \mathrm{d} v+\left\{\left[f_{1}(v) v-f(v)\right] / q\right\} \mathrm{d} q .
$$

To obtain a necessary and sufficient condition for $\mathrm{d} u / \mathrm{d} q>0$, combine the total differentials of (A6) and (A7) so that

$$
\begin{aligned}
\beta F_{11}(x)\left([q f(v)]^{2} / v\right) \mathrm{d} u & =\left[\frac{F_{11}(x) x}{F_{1}(x)} \frac{1-f_{1}(v) v / f(v)}{f_{11}(v) v / f_{1}(v)}-1\right] \mathrm{d} q \\
& =\left[\left(\mathrm{d} \ln F_{1}(x) / \mathrm{d} \ln x\right) \frac{1-(\mathrm{d} \ln f(v) / \mathrm{d} \ln v)}{\mathrm{d} \ln f_{1} / \mathrm{d} \ln v}-1\right] \mathrm{d} q .
\end{aligned}
$$

Observe $F_{11}(x)<0$ and $\mathrm{d} \ln f_{1}(v) / \mathrm{d} \ln v<0<\mathrm{d} \ln f(v) / \mathrm{d} \ln v<1$. By rearranging, a necessary condition for $\mathrm{d} u / \mathrm{d} q>0$ emerges as follows: that the marginal product of energy services be inelastic with respect to energy services and the energy efficiency be relatively elastic compared to the marginal energy efficiency each with respect to the capital intensity of energy. The condition holds, if $f$ and $F$ are strictly concave power functions as assumed in the model. This can be shown with $\mathrm{d} \ln F_{1}(x) / \mathrm{d} \ln x=\alpha(1-\gamma)-1, \mathrm{~d} \ln f(v) / \mathrm{d} \ln v=\varepsilon$, and $\mathrm{d} \ln f_{1}(v) / \mathrm{d} \ln v=\varepsilon-1$. Consider now the effect of $p$ on $u$. An increase in $p$ raises the right side in (A7). To restore equality, the capital intensity of energy $v$, and so the energy efficiency $f(v)$, must increase. This implies the effects discovered as the indirect effects from an increase in investment-specific productivity above in (A6). Hence, energy use must decline.

Consider now the effects of $q$ and $p$ on energy services $x$. An increase in $q$ raises energy efficiency $f(v)$ and enhances energy use $u$. Clearly, this implies an increase in $x$. An increase in $p$, through increasing energy efficiency, raises the left side in (A6). To restore equality of both sides, energy services $x$ must decrease. QED

Proof of Proposition 2 
Parts i, ii, and $\mathrm{v}$ can be immediately obtained from (20), since $\gamma_{z}>0$. To obtain parts iii and iv, note that $\tilde{g} \gamma_{\varphi}>1$ can be equivalently stated as $\gamma_{1 / p} \gamma_{\varphi}>1$. QED

\section{Proof of Corollary 1}

Use Proposition 2(v), and that with a declining capital price $(1 / q)$ and an increasing energy price $p$ (so that $\gamma_{1 / p}<1<\gamma_{q}$ ), the growth factor of energy absent neutral technological change, $\tilde{g}$, can be less than, equal to, or greater than one. QED

\section{Appendix B: Data}

This appendix describes the construction of the data series used in the paper measuring variables in the model and details the construction of investment-specific technology. The Online Appendix contains additional information.

We begin the description of the model measurement with the energy use and energy price $\left(e, u_{M}\right.$ (or $u$ ), and $u_{N}$, and $p$ ), continue with the investment-specific shift in technology $\left(q_{M}\right.$ (or $\left.q\right)$ and $\left.q_{N}\right)$, the fraction of time worked and output in the market $(\ell$ and $y)$, and conclude with investment $\left(\int i_{d}(v) \mathrm{d} v, \int i_{m}(v) \mathrm{d} v, i_{k}\right.$, and $\left.i_{r}\right)$ and capital stock $\left(\int m(v) \mathrm{d} v\right.$, $\int d(v) \mathrm{d} v, k$, and $\left.r\right)$.

Model in Section II:

$e$ and $u$-Energy use by private businesses and households, and energy use by private businesses, relative to hours available for work and leisure.

$p$-Deflator for energy used by businesses and households relative to common deflator.

$q$ - Common deflator divided by deflator for investment in private nonresidential equipment.

$\ell$ - Hours worked divided by hours available for work and leisure.

$y$ - Gross national product less nonfarm owner-occupied housing output divided by common deflator and hours available for work and leisure.

$\int i_{m}(v) \mathrm{d} v$ and $i_{k}$-Investment in private nonresidential equipment and structures not for energy production, relative to common deflator and hours.

$\int m(v) \mathrm{d} v$ and $k$-Current-cost net stock of private nonresidential equipment and structures less such stock in energy production, relative to the one-period lagged values of deflator for the corresponding investment and hours.

Additional and replacing variables in Section VI.A:

$u_{M}$ and $u_{N}$-The same as $u$ and energy use by households relative to hours, the same as $(e-u)$.

$q_{M}$ and $q_{N}$ - Common deflator divided by deflator for investment in private nonresidential equipment not for energy production and expenditure on durable consumption goods.

$\int i_{d}(v) \mathrm{d} v$ and $i_{r}$-Expenditure on durable consumption goods and investment in residential structures, relative to common deflator and hours available for work in the market and the household. 
TABLE B1

q-REgRessions, OLS METHOD, 1947-1983

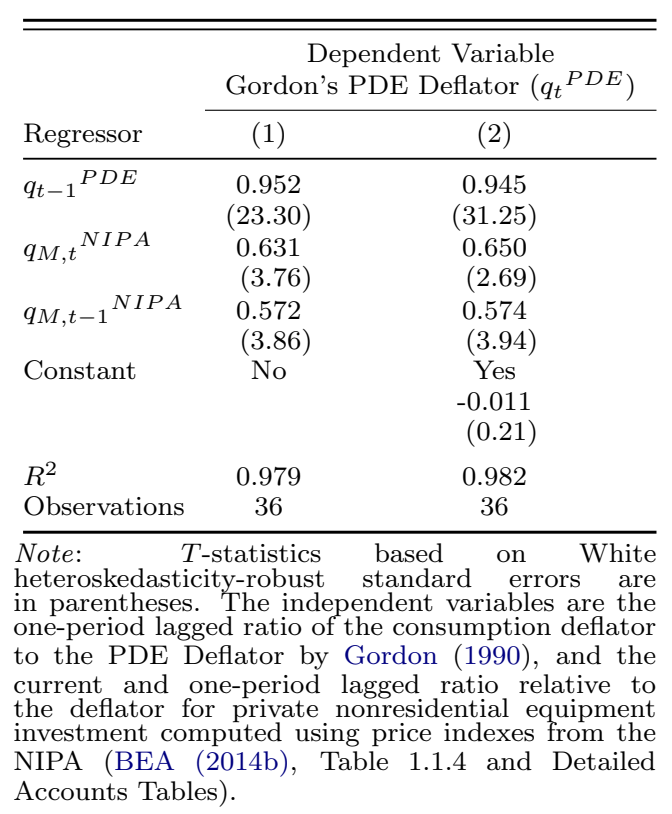

$\int d(v) \mathrm{d} v$ and $r$-Current-cost net stock of durable consumption goods and residential structures, relative to the one-period lagged values of the deflator for the corresponding expenditure and investment and hours.

We now provide a detailed description of our procedure of the construction of investmentspecific technology.

To measure the investment-specific technology $q_{M}$ and $q_{N}$ for new energy-using capital (private nonresidential equipment capital and nondurable consumption goods), we need to find values for their implicit deflators. For the period 1960-1983, the investment-specific technology $q_{M}$ is the common deflator $P_{c}$ relative to Gordon's (1990) producer durable equipment (PDE) price index for business equipment (available for the period 1947-1983), $q^{P D E}$. For the period 1984-2011, $q_{M}$ is the forecast of the dependent variable $q^{P D E}$ in the autoregressive model

$$
q_{t}^{P D E}-a q_{t-1}^{P D E}=b\left(q_{M, t}{ }^{N I P A}-(c / b) q_{M, t-1}{ }^{N I P A}\right)+u_{q, t},
$$

using the independent variable $q_{M}^{N I P A}$ and the normally distributed error term $u_{q}$. We measure the independent variable $q_{M}{ }^{N I P A}$ as the common deflator relative to the NIPA deflator for private nonresidential equipment investment. Column 1 in Table B1 presents the estimated values of the coefficients $a, b$, and $c$. A specification with constant term, appearing in Column 2 in Table B1, is ruled out because the constant is insignificantly different from zero at the five-percent significance level.

To form the NIPA equipment investment deflator, we account for heterogeneous prices for equipment investment in capital involved and not involved in energy production. The NIPA equipment investment deflator is formed by using the BEA's chain-weighting pro- 
TABLE B2

Growth FACtors of Investment-SPECIFIC TeChNology

\begin{tabular}{|c|c|c|c|c|}
\hline \multirow[b]{3}{*}{ Data } & \multicolumn{2}{|c|}{ Businesses } & \multicolumn{2}{|c|}{ Households } \\
\hline & $\begin{array}{l}\text { Equipment } \\
\text { Investment }\end{array}$ & $\begin{array}{c}\text { Nonresidential } \\
\text { Structures } \\
\text { Investment }\end{array}$ & $\begin{array}{c}\text { Durable } \\
\text { Consumption } \\
\text { Goods }\end{array}$ & $\begin{array}{c}\text { Residential } \\
\text { Structures } \\
\text { Investment }\end{array}$ \\
\hline & 1960-2011 & $1960-2011$ & 1960-2011 & 1960-2011 \\
\hline BEA & 1.027 & 0.995 & 1.026 & 0.998 \\
\hline Adjusted & 1.031 & 1 & 1.032 & 1 \\
\hline
\end{tabular}

Note: Average annual gross rate of change in the nondurable consumption and nonhousing services deflator relative to the respective investment or durable consumption goods deflator.

cedure to combine the deflator for aggregate private nonresidential equipment investment in Table 1.1.4, the deflators for investment in equipment capital used for energy production in Detailed Accounts Tables, and the associated current-value flows (see below for a description of components).

We compute the productivity of using factors for new energy-using capital used in households (durable consumption goods) relative to market consumption goods $q_{N}$ by ratio splicing the NIPA deflator for durable consumption goods with the deflator implied by $q_{M}$ relative to the NIPA deflator for private nonresidential equipment, $q_{N}=q_{N}{ }^{N I P A} q_{M} / q_{M}{ }^{N I P A}$. We let $q_{N}{ }^{N I P A}$ be the common deflator relative to the NIPA deflator for durable consumption goods taken from Table 1.1.4. ${ }^{38}$

Table B2 shows the average annual rates of change of investment-specific technology in the NIPA data from the BEA and adjusted series.

We adjust the deflators for nonresidential and residential structures so to obtain prices for nonresidential and residential structures equal to 1 over the whole sample period. In the NIPA data of the 1960-2011 period, the implied inverse of the shift in investment-specifc technology increased by less than one percent on average per year, as Table B2 shows. In contrast, over the 1959-1996 period, Gort, Greenwood, and Rupert (1999) estimate one percent growth of productivity in structures creation relative to market consumption. Our choice of the deflator for structures thus reflects an intermediate value between these estimates.

The Online Appendix contains additional information on the construction of energy use and energy price, hours of work and output, investment, and capital stock. In addition, the Online Appendix reports on the measurement of real-cost capital stock.

\footnotetext{
${ }^{38}$ Krusell, Ohanian, Ríos-Rull, and Violante (2000), in an analysis of skill-biased technical change, use forecasts from extrapolating all but the price of the computer component of equipment. The use of computer price indexes is majorly responsible for the steeper increase in $q$ 1980-1992 compared to 1963-1979 in their sample. Computers constitute one of many types of energy-using equipment, so we omit such detailed consideration.
} 


\section{ONLINE APPENDIX for "Does Higher Energy Efficiency Lower Economy-Wide Energy Use?"}

This appendix contains additional information on proving Proposition 1, the measurement of the model and real-cost capital stock, an analysis of technology residuals, the extension of the model to household energy use, and provides conditions for examining the robustness of our results to capital utilization.

\section{Additional Results}

For the proof of Proposition 1 in the paper, it is useful to first prove the following Lemma for increasing, strictly concave, and twice-differentiable functions $f$ and $F$, so that $f_{11}<0<f_{1}$ and $F_{11}<0<F_{1}$, using the second-order and first-order derivatives, and $\lim _{x \rightarrow 0} F_{1}(x)=\infty$. With $F(x) \equiv G(k, x, z \ell)$ at constant $k$ and $z \ell, F_{11}=G_{22}$ and $F_{1}=G_{2}$.

LEMMA O.1: There is a unique interior steady state $\left(c, i_{m}(v), x, u\right)$ characterized by investment of exactly one type $v$ in the simplified setup.

Proof. We first show that investment $\left(i_{m}(v)\right)$, energy services $(x)$, and energy use $(u)$, are positive at a solution to $\mathrm{P}(1)$ and $\mathrm{P}(2)$. Observe the first-order necessary condition $q\left[\mu_{x} f(v)-\mu_{u}\right] / v \leq 1$ choosing investment $i_{m}(v) \geq 0$ all $v \in(0, \infty)$, using the Lagrange multipliers $\mu_{x} \geq 0$ and $\mu_{u} \geq 0$ on (9) and (10). Using the expression for the constant equity return rate $\left(\psi^{\prime}+\delta^{\prime}\right) / \psi=1 / \beta$, the first-order necessary conditions for energy services and energy use read

$$
\begin{aligned}
& \mu_{x} \geq \beta F_{1}(x), \quad=\text { if } x>0, \\
& \mu_{u} \leq \beta p, \quad=\text { if } u>0 .
\end{aligned}
$$

The shadow price $\mu_{u}$ is finite as the marginal cost of energy is finite, $p<\infty$. Both $f(v) / v$ and $1 / v$ are finite by assumption. The shadow price $\mu_{x}$ approaches the value infinity if energy services go to zero, $x=0$, since $\lim _{x \rightarrow 0} F_{1}(x)=\infty$. Thus, the first-order necessary condition of investment would be violated with $x=0$. Hence, $x>0$, implying $i_{m}(v)>0$ some $v \in(0, \infty)$, and in turn yielding $u>0$.

We can now show existence and uniqueness in four steps.

Step 1. Lemma A.1, using the strict concavity of $f$, implies that investment occurs in at most one type $v$. The fact that investment occurs in some type then implies uniqueness of the type.

Step 2. Investment requires energy use, $u>0$, so that condition (O.2) holds at equality. (Condition (O.2) at equality then uniquely determines $v \in(0, \infty)$ with the marginal benefit of energy $\mu_{u}=\left[f-f_{1} v\right] / q f_{1}$.)

Step 3. We now show that there is a unique level of investment $i_{m}(v) \in(0, \infty)$. The marginal benefit of energy services, $F_{1}(x)$, decreases in energy services $x$, and thus in investment $i_{m}(v)$, given capital intensity of energy $v$. There exists a unique positive level of investment $i_{m}(v)$ satisfying (O.1) at equality, if $F_{1}$ is sufficiently large for small $x$ and small for large $x$.

Step 4. The laws of motion (9) and (10) at a steady state evaluated at unique investment $i_{m}(v)$ and capital-energy ratio $v$ then imply unique energy services $x$ and energy use $u$. 
Consumption $c$ then follows uniquely from the resource constraint $c+\int i_{m}(v) \mathrm{d} v+p u /(1-$ $\omega)=F(x)$. QED

\section{Data}

This section reports on the construction of variables in the model and the measurement of real-cost capital cost.

Energy Use, Energy Price.-Energy use is a composite of primary energy from coal, oil, and natural gas, and biomass energy net of their use in electricity production, and of electricity. The energy price $p=P / P_{c}$ is the ratio of the energy deflator $P$ to the consumption deflator $P_{c}$. The energy deflator $P$ equals the weighted average of deflators for market and household energy use $p_{M}$ and $p_{N}$. With the weights being the portion of energy use in the sectors $M$ and $N$ of total energy use, $P=\left(p_{M} u_{M}+p_{N} u_{N}\right) /\left(u_{M}+u_{N}\right)$.

The deflator for energy in sector $j \in\{M, N\}$ is the Laspeyres constant price index, $p_{j, t}=\sum_{i \in \mathcal{I}_{j}} P_{i, t} E_{i, t} / \sum_{i \in \mathcal{I}_{j}} P_{i, b} E_{i, t}$, with the set $\mathcal{I}_{j}$ and base period $b$. We use the year 2009 as the base period (for all deflators). The deflator $P_{i, b}$ is the mean price relative to the mean price of one type of energy (coal used in the Industrial sector). We obtain real energy use as $u_{j, t}=\sum_{i \in \mathcal{I}_{j}} P_{i, b} E_{i, t}$ for $j \in\{M, N\}$. The deflator for sectoral energy thus aggregates specific energy deflators and quantities. The deflator $P_{i, t}$ (for primary energy not used fo electricity production, and for electricity) at date $t$ corresponds to the date- $t$ price in an institutional sector $i$ in the data. We find the prices for biomass, coal, petroleum, and natural gas in $A E R$ Table 3.1 and $S E D S$ various tables. We use the electricity retail price by sector. The corresponding quantity of energy use $E_{i, t}$ we measure as the Commercial, Industrial, Transportation sectors' energy consumption including of electricity use from AER Tables 2.1a-d, 8.4a, and 8.4c. ${ }^{39}$ We account for electricity production in the different institutional sectors. To form electricity use, electricity produced in the Commercial and Industrial sectors is added to electricity consumed by these sectors. We sort the resulting Commercial and Industrial sector energy use to market energy use, Residential sector energy use to household energy use, and, in this manner, Electricity sector sale to the Commercial, Industrial, and Residential sectors to market and household energy use. We account each a share of Transportation energy use to the market and household energy use. To obtain the share, we use Highway Statistics on motor gasoline. The energy price and quantity series include renewable energy through biomass and electricity. ${ }^{40}$

The common deflator $P_{c}$ is the Törnqvist index of nondurables consumption and nonhousing services (in contrast to the services in the model).

Hours of Work and Output. - To measure work time $\ell$, we divide hours of work by the available time for work and leisure. Available time for work and leisure is assumed 16 hours per day for 365 days per year for each member of the noninstitutional population aged 1664. Aggregate market output corresponds to gross national product less the imputed rental income for owner-occupied housing in the NIPA.

Hours of work are taken from Cociuba, Prescott, and Ueberfeldt (2012), representing the

\footnotetext{
${ }^{39}$ Hassler, Krusell, and Olovsson (2012) form a Laspeyres price index with the average relative price among energy resources. An alternative to the average relative price among energy resources is a base price in some period as in Atkeson and Kehoe (1999). Both these routes produce very similar indexes.

${ }^{40}$ The series of prices $p_{M, t}$ and $p_{N, t}$ are very similar to each other.
} 
time used for work by the noninstitutional population aged 16-64, based on data from the Bureau of Labor Statistics. The hours of work include hours worked by military personnel consistent with the model assuming that government military expenditure is consumed by households. GNP is taken from the NIPA Table 1.1.5. The value for owner-occupied housing comes from Table 7.4.5. We depart from the literature by not deducting energy sector value added from GNP, because the model is a reduced form of a model with the use of capital and labor in intermediate energy production. Energy expenditure (pe) would equal energy value added in a model with energy production using these primary factors. The expenditure in our model simply proxies for investment excluded.

Investment.-The model abstracts from a sector that produces energy, for example, in coal mines, oil and gas wells, and electricity generation plants. From the gross equipment investment, we therefore deduct equipment investment from the sectors Oil and Gas Extraction (all) and Utilities (the components Nuclear fuel, Steam engines, and Electric transmission and distribution). From the gross structures investment, we deduct structures investment from the sectors Oil and Gas Extraction (all) and Utilities (the component accounted for by the type Electric). To measure investment in capital used in household production, we use the gross values for expenditure on durable consumption goods and investment in residential structures capital.

We use private nonresidential equipment investment, nonresidential structures investment, durable consumption goods expenditure, and residential structures investment from the NIPA Table 1.1.5. The energy sector investment series come from Detailed Sectoral Accounts. Importantly, we form new chain-type quantity indexes for investment using the chain-type quantity indexes for the corresponding gross values and substracted values.

Capital Stock.-To measure capital used in the market in the model, the value of capital used in energy resource and electricity production must be deducted from the gross value of capital in the data. We choose the same categories as for adjusting private nonresidential equipment and structures. Each capital stock after adjustment for the energy sector equals the ratio of current-cost capital stock to the one-period lagged values for the corresponding investment deflator and hours, see below. (We base the investment deflator on the deflator for gross investment and chain-type quantity indexes of the investment in the capital stock deducted). The values for the capital stocks so obtained are used to find the average depreciation rates (see Section IV). The capital stocks are then constructed by solving their laws of motion forward starting with the initial value based on the deflator of capital adjusted for a bias in the relative deflators of consumption and investment (see above) and employing the computed depreciation rates.

Figure O.1A plots both the real nonresidential capital stock from the NIPA data and the real stock used here. Figure O.1B shows the corresponding series for household capital. The NIPA values for the structures-specific productivity have declined, so that less structures capital is measured at the initial date with the adjustment for the bias in the relative deflators of consumption and investment.

We use the current-cost capital stock from FAA Table 1.1. The deflator for gross investment comes from the NIPA Table 1.1.4.

Measurement of Real-Cost Capital Stock.-We now provide more detail on our method of measuring real-cost capital stock using current-cost net stock and a deflator for new capital in the data, and derive physical depreciation of capital per available working hour. 
(A) Equipment and Nonresidential Structures
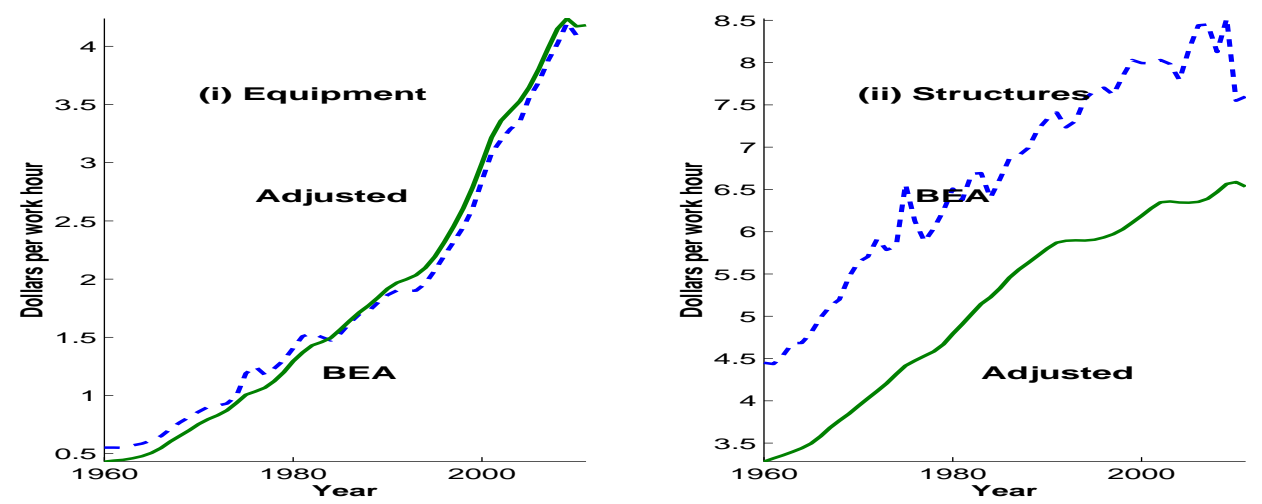

(B) Durable Consumption Goods and Residential Structures
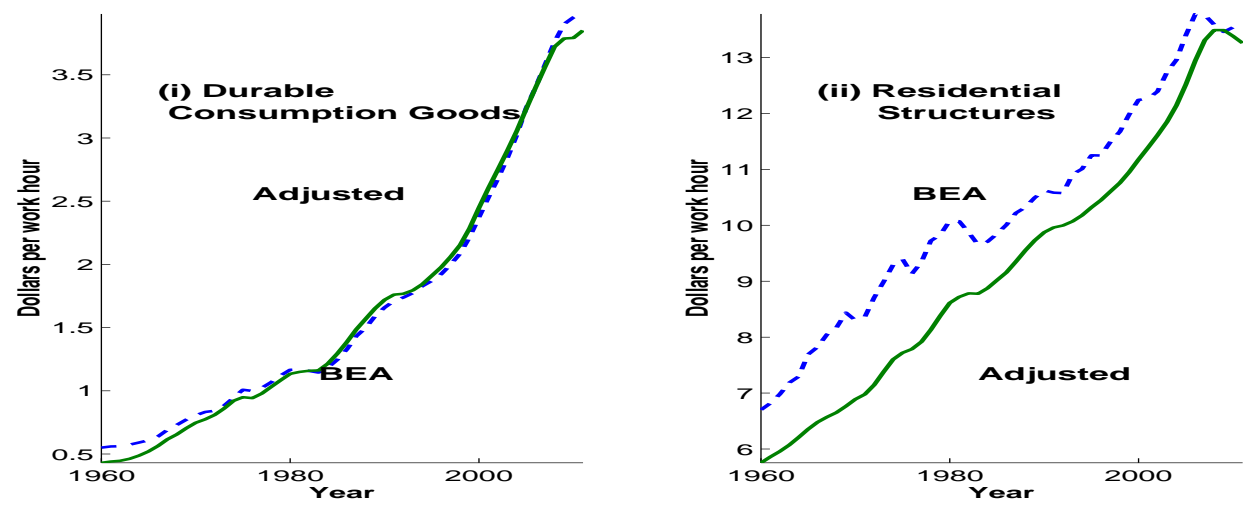

Fig O.1. Capital Stock 1960-2011: (A) Equipment and Nonresidential Structures; (B) Durable Consumption Goods and Residential Structures

The service capital of vintage $v$ produces at date $t$ (equal to its value) will be denoted by $i_{v}(t)$. All other variables have a subscript for the date. With geometric depreciation factor $\chi$, the date- $t$ price of capital of vintage, $v \leq t-1$, equals $\chi^{t-v-1}$ times the price of capital of the most recent vintage, $P_{i, t-1}$. At the beginning of period $t$, the current-cost capital stock then is

$$
K_{t} \equiv P_{i, t-1}\left(i_{t-1}(t)+\chi i_{t-2}(t)+\chi^{2} i_{t-3}(t)+\ldots\right) .
$$

Thus, to form the real-cost capital stock $k_{t}^{\text {real }} \equiv K_{t} / P_{i, t-1}$, we divide the current-cost capital stock, $K_{t}$, by the one-period lagged price of investment goods, $P_{i, t-1}$. We measure current-cost investment in the data given by $I_{t}=P_{i, t} i_{t}(t+1)$ and define real investment as $i_{t}{ }^{\text {real }} \equiv\left(1 / P_{c, t}\right) I_{t}$. Shifting forward the identity $i_{t-1}(t)+\chi i_{t-2}(t)+\chi^{2} i_{t-3}(t)+\ldots=$ $\chi\left(i_{t-2}(t)+\chi i_{t-3}(t)+\ldots\right)+i_{t-1}(t)$ by one period implies the law of motion of the real-cost 
(A) Energy-using CAPital

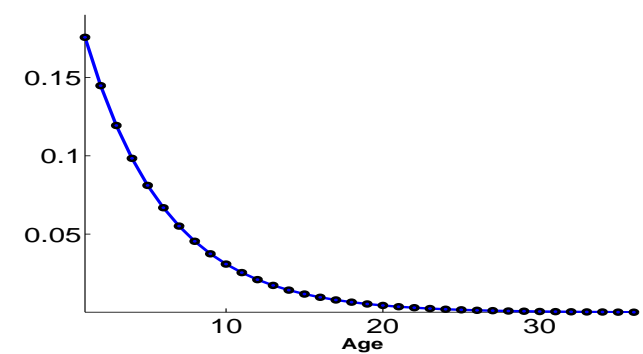

Fig O.2. Steady-STate Distributions:
(B) ENERGy Use

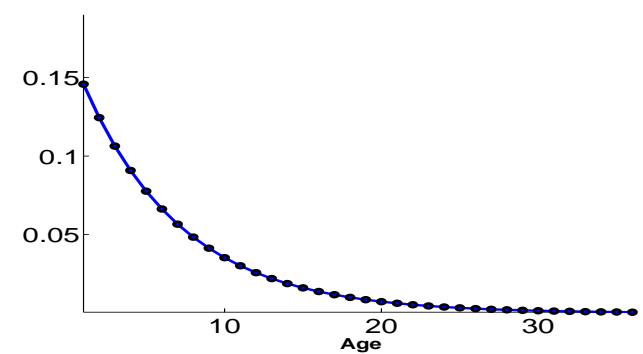

(A) Energy-using Capital; (B) Energy Use

capital stock,

$$
k_{t+1}{ }^{r e a l}=\chi k_{t}^{r e a l}+\left(P_{c, t} / P_{i, t}\right) i_{t}^{\text {real }} .
$$

To consistently measure inputs and outputs per hour available for work, we obtain realcost capital stock per hour as $K_{t+1} /\left(P_{i, t} \mathrm{H}_{t}\right)$ and real investment per hour as $I_{t} /\left(P_{c, t} \mathrm{H}_{t}\right)$ using hours available for work $\mathrm{H}$, so that

$$
K_{t+1} / P_{i, t} \mathrm{H}_{t}=\chi\left(\mathrm{H}_{t-1} / \mathrm{H}_{t}\right) K_{t} /\left(P_{i, t-1} \mathrm{H}_{t-1}\right)+\left(P_{c, t} / P_{i, t}\right) I_{t} /\left(P_{c, t} \mathrm{H}_{t}\right) .
$$

The procedure outlined here is useful to measure capital in the model by $k_{t}^{\text {real }} / \mathrm{H}_{t-1}$ and investment in the model by $i_{t}^{\text {real }} / \mathrm{H}_{t}$, and the depreciation factor in the model by $\chi\left(\mathrm{H}_{t-1} / \mathrm{H}_{t}\right)$.

Our method of finding real-cost capital stock and depreciation thus accounts for investmentspecific technology in the NIPA data.

\section{Technology Residuals}

Labor efficiency can be found given the calibrated production function of market output and data as a residual; by plugging in values for nonenergy-using capital, energy services, working hours, and output. There are, however, no time-series data on economy-wide energy services.

To find values for energy services, we compute a counterpart to the model imposing onto the data laws of motion of the model with a unique type of energy-using capital invested. We thus find the distribution of capital over energy efficiency types for each date on the sample period.

\section{The Procedure}

First, the distribution of capital and energy over types of the capital intensity of energy expresses the distribution of (energy-using) capital and energy over age as agents invest in only one type of the capital intensity of energy at a given date. We distribute the capital and energy use in the data at the initial sample date over types according to the steady-state age distribution of capital and energy with truncation at age of 200 years. On a balanced 


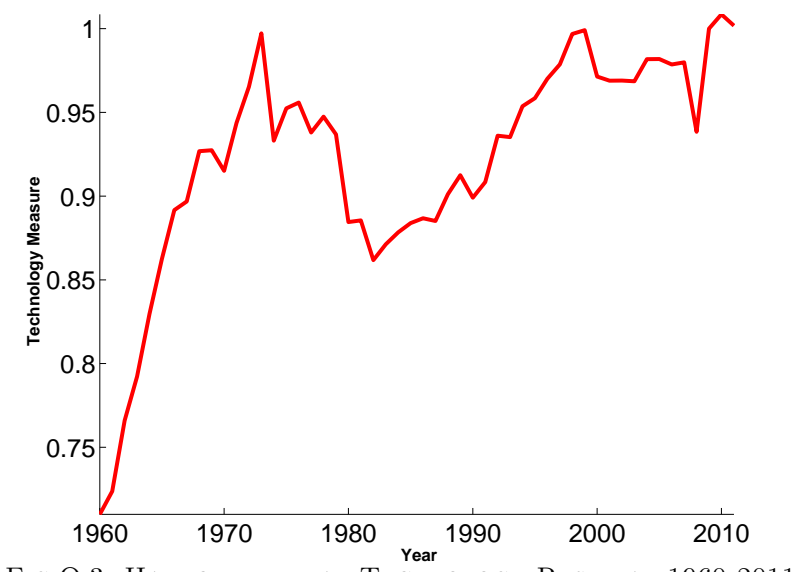

Fig O.3. Harrod-neutral Technology Residual 1960-2011

growth path, the distribution of energy-using capital over age is given by the summands in $\int m^{\prime}(v) \mathrm{d} v=\left(q \int i_{m}(v) \mathrm{d} v\right)\left\{\sum_{\tau=1}^{\infty}\left[\left(1-\delta_{m}\right) / g \gamma_{q}\right]^{\tau-1}\right\}$, where $q i_{m}(v)\left[\left(1-\delta_{m}\right) / g \gamma_{q}\right]^{\tau-1}$ denotes the energy-using capital aged $\tau$ periods from the date of its construction until the date with capital $\int m^{\prime}(v) \mathrm{d} v$ and $\int i_{m}(v) \mathrm{d} v$ denotes investment in capital one period ago. On a balanced growth path, the distribution of energy over age is given by the summands in $u^{\prime}=\left(q \int\left[i_{m}(v) / v\right] \mathrm{d} v\right)\left\{\sum_{\tau=1}^{\infty}\left[\left(1-\delta_{m} / g \gamma_{1 / p}\right]^{\tau-1}\right\}\right.$, where $\left(q \int\left[i_{m}(v) / v\right] \mathrm{d} v\right)\left[\left(1-\delta_{m}\right) / g \gamma_{1 / p}\right]^{\tau-1}$ denotes the energy requirement of age- $\tau$ capital at the date with aggregate energy use $u^{\prime}$. The distributions of capital and energy over capital age relative to their total amounts are thus time-invariant. We use the elements with $\tau \in\{1,2, \ldots, T\}$ and set $T=200$. Figures $\mathrm{O} .2 \mathrm{~A}$ and $\mathrm{O} .2 \mathrm{~B}$ portray the age distributions of capital and energy based on the calibrated model.

The distribution of energy-using capital and their energy requirement in household production along a balanced growth path follow analogously.

Second, we track the age distributions of capital and energy over the sample period by using the energy efficiency of new capital vintages. To obtain energy efficiency, we form the capital intensity of energy of new capital vintages. To compute the capital intensity of energy, we insert the data on capital and energy into the left sides of Equations (6) and (10) - that equation related to capital summed over capital intensity types. This yields an expression for the right sides. The measured capital-energy ratio in the market $v$ then equals the quotient of the right side of the laws of motion (6) and (10). We thus utilize that the agents in the model invest in capital with a unique capital intensity of energy at each date.

Third, energy services over the sample period are found by summing energy times the energy efficiency over vintages for each date (energy $m(v) / v$ and energy efficiency $f(v)$ ).

Figure O.3 displays the Harrod-neutral technology, or labor efficiency, that we computed as residual.

\section{Analysis}

We can use the Harrod-neutral technology series to gauge the behavior of energy use and services relative to neutral technology. 


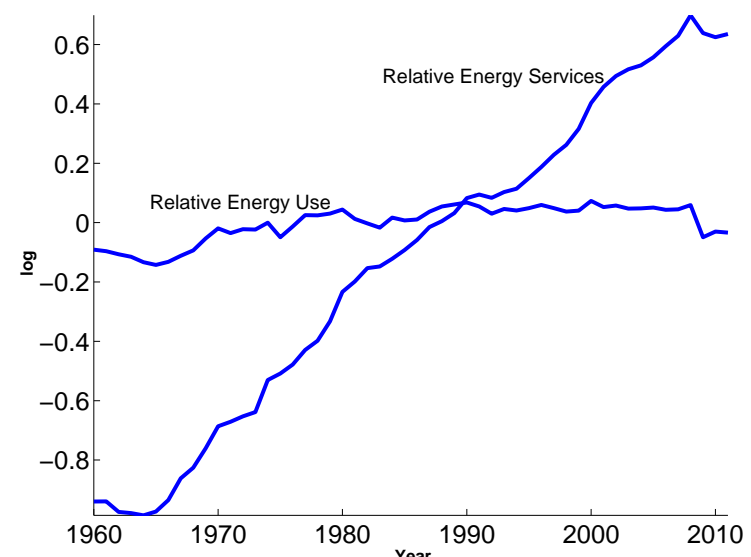

Fig O.4. Energy Use and Services Relative to Neutral Technology U.S. 1960-2011

Notes: The series are demeaned and in logarithms. See the Appendix C for the construction of energy services $x$ which led to the construction of the neutral technology measure $z$.

Using balanced growth relationships is valid if the variables constructed are on average around a balanced growth path, not necessarily on the path. Thus smooth energy use and services are not necessary to use balanced growth relationships to account the effect of energy-saving technological change on the change of energy use. Interestingly, energy use and energy services relative to Harrod-neutral technology measured as residual, portrayed in Figure O.4, have smooth experiences. The relative energy use is much smoother than energy use, because the slowdown in energy use in the 1980's coincides with the productivity slowdown, as can be seen from Figures 1B and O.3.

\section{Household Production}

This appendix presents the economic environment, defines an equilibrium, provides firstorder necessary conditions for an equilibrium, and presents the calibration for the extended model with household production.

\section{The Economic Environment in Section VI.A}

In each period, households are endowed with one unit of time which they can supply as labor to the production of market and home goods, and can consume market consumption, $c_{M}$, and home consumption, $c_{N}$. Preferences are thus expressed by $J_{0}=$ $\mathbb{E}_{0}\left[\sum_{t=0}^{\infty} \beta^{t} U\left(c_{M, t}, c_{N, t}\right)\right]$ so that a balanced growth path exists with no cross-sectoral restriction on technological change. ${ }^{41}$

The market good is produced according to (3)-(5) with energy use $u=u_{M}$, energy services $x=x_{M}$, and labor efficiency $z=z_{M}$, and given the elasticity of energy efficiency with respect to the capital-energy ratio $\varepsilon=\varepsilon_{M}$. In a symmetric way, households combine

\footnotetext{
${ }^{41}$ The unitary elasticity of substitution between market and home consumption allows unequal growth of market and home consumption along a balanced growth path. For other values of the elasticity of substitution, growth of output from the market and home are equal, which restricts the rates of technological change on a balanced growth path to a surface that may not contain the desired set of counterfactual rates of energy-saving technological change.
} 
nonenergy-using capital $\tilde{r}$, energy services $x_{N}$, and labor $(1-\ell)$ to produce the home consumption good

$$
c_{N}=H\left(\tilde{r}, x_{N}, z_{N}(1-\ell)\right)=\tilde{r}^{\lambda \zeta} x_{N}^{\lambda(1-\zeta)}\left(z_{N}(1-\ell)\right)^{1-\lambda},
$$

with the distribution parameters $0<\lambda, \zeta<1$ and exogenous labor efficiency $z_{N}>0 .{ }^{42}$ Households use varieties of capital goods $d(v)$ and energy $d(v) / v$ to produce the home energy services $x_{N}$ with type- $v$ energy efficiency $h(v)=v^{\varepsilon_{N}}, 0<\varepsilon_{N}<1$. Production of household energy services and the energy use required are given by $x_{N}=\int \frac{1}{v} d(v) h(v) \mathrm{d} v$ and $u_{N}=\int \frac{1}{v} d(v) \mathrm{d} v$. Economy-wide energy use then can be stated as $e=u_{M}+u_{N}$.

The laws of motion of capital stocks used in household production are analogous to those in market production (with $q=q_{M}$ ). Capital stocks depreciate with geometric rates $\delta_{d}$ and $\delta_{r}$ and can be enhanced with investment $i_{d}(v) \geq 0$ and $i_{r} \geq 0$,

$$
\begin{gathered}
d^{\prime}(v)-\left(1-\delta_{d}\right) d(v)=q_{N} i_{d}(v), \\
\tilde{r}^{\prime}-\left(1-\delta_{r}\right) \tilde{r}=i_{r},
\end{gathered}
$$

where prime denotes the next period's value and $q_{N}$ denotes investment-specific technology.

The market good can be used for consumption, investment in capital stock, and energy purchases,

$$
c_{M}+\int\left[i_{d}(v)+i_{m}(v)\right] \mathrm{d} v+i_{r}+i_{k}+p e=y
$$

Market and home production functions have the Cobb-Douglas form, and hence a unitary elasticity of substitution. ${ }^{43}$

The model in Section II thus arises for no use of capital in household production $(\lambda=0)$, no investment in household capital stock $\left(i_{d}(v)=0\right.$ all $\left.v, i_{r}=0\right)$, unitary efficiency of use of time in the household $\left(z_{N}=1\right)$, and exogenous portion of market energy use in economywide energy use (exogenous $u_{M} /\left(u_{M}+u_{M}\right)$ ).

\section{Equilibrium in Section VI.A}

To continue, we now formulate decentralized decision-making and define an equilibrium.

\footnotetext{
${ }^{42}$ Labor efficiency can be unequal in the business and household sector. The use of time at home can be viewed as inherently desirable, being enriched with home capital services, consistent with the view that households have preferences for leisure.

${ }^{43}$ Within the constant elasticity of substitution (CES) family of production functions, complementary inputs in home production require that household durable goods services in our model increase at the same rate as household labor efficiency along a balanced growth path. This precludes that the marginal product of investment in durable goods services $q_{N} h(v) / v$ with chosen capital intensity of energy by households $v$ changes along a balanced growth path, implying that the rates of change in investment-specific productivity $q_{N}$ and the energy price $p$ are connected, which would restrict counterfactuals.
} 
We use the laws of motion of energy services and use in households

$$
\begin{aligned}
x_{N}{ }^{\prime}-\left(1-\delta_{d}\right) x_{N} & =\int \frac{h(v)}{v} q_{N} i_{d}(v) \mathrm{d} v, \\
u_{N}{ }^{\prime}-\left(1-\delta_{d}\right) u_{N} & =\int \frac{1}{v} q_{N} i_{d}(v) \mathrm{d} v .
\end{aligned}
$$

Both households and firms supply the stocks of nonenergy-using capital, energy services, and energy use to themselves. The exogenous state $\triangle_{M, N}$ contains the energy price $p$, investment-specific productivity $\mathrm{q}=\left(q_{M}, q_{N}\right)$, and labor efficiency $\mathrm{z}=\left(z_{M}, z_{N}\right)$. The endogenous components in the aggregate state of the world $\epsilon=\left(\mathrm{k}, \mathrm{r}, \mathrm{x}_{M}, \mathrm{x}_{N}, \mathrm{u}_{M}, \mathrm{u}_{N}, \mathrm{~s}, \triangle_{M, N}\right)$ evolve as $\left(\mathrm{k}^{\prime}, \mathrm{r}^{\prime}, \mathrm{x}_{M}^{\prime}, \mathrm{x}_{N}^{\prime}, \mathrm{u}_{M}^{\prime}, \mathrm{u}_{N}^{\prime}, \mathrm{s}^{\prime}\right)=\Theta(\epsilon) \equiv\left(K(\epsilon), \tilde{R}(\epsilon), X_{M}(\epsilon), X_{N}(\epsilon), U_{M}(\epsilon), U_{N}(\epsilon), S(\epsilon)\right)$. The households and firms take this motion as exogenously given.

The government budget constraint (11) remains unchanged with dividend tax rate $\tau_{\delta}$, labor income tax rate $\tau_{w}$, and lump-sum payment $\tau$. A competitive equilibrium can now be defined.

1. The Decision Problem of Households.-The goal of a representative household is solving the problem

$$
\begin{array}{r}
J\left(r, x_{N}, u_{N}, \tilde{s}, \epsilon\right)=\max _{c_{M},\left(i_{d}(v)\right), \ell, \tilde{r}^{\prime}, x_{N^{\prime}}, u_{N^{\prime}}, \tilde{s}^{\prime}}\{ \\
+\beta\left(c_{M}, H\left(\tilde{r}, x_{N}, z_{N}(1-\ell)\right)\right) \\
\left.+\beta \mathbb{E}\left[J\left(\tilde{r}^{\prime}, x_{N^{\prime}}{ }^{\prime}, u_{N}{ }^{\prime}, \tilde{s}^{\prime}, \epsilon^{\prime}\right)\right]\right\}
\end{array}
$$

subject to (a) the budget constraint,

$$
\begin{aligned}
c_{M} & +\tilde{r}^{\prime}-\left(1-\delta_{r}\right) \tilde{r}+\int i_{d}(v) \mathrm{d} v+p u_{N}+\Psi(\epsilon) \tilde{s}^{\prime} \\
& =\left[\Psi(\epsilon)+\left(1-\tau_{\delta}\right) D(\epsilon)\right] \tilde{s}+\left(1-\tau_{w}\right) W(\epsilon) \ell+T(\epsilon),
\end{aligned}
$$

(b) the laws of motion of home energy services and use (O.7) and (O.8), and (c) the law of motion of the endogenous aggregate state $\left(\mathrm{k}^{\prime}, \mathrm{r}^{\prime}, \mathrm{x}_{M}^{\prime}, \mathrm{x}_{N}^{\prime}, \mathrm{u}_{M}^{\prime}, \mathrm{u}_{N}^{\prime}, \mathrm{s}^{\prime}\right)=\Theta(\epsilon)$, taking as given dividend $\delta=D(\epsilon)$, prices $w=W(\epsilon), \psi=\Psi(\epsilon)$, and transfers $\tau=T(\epsilon)[\mathrm{P}(3)]$.

2. The Decision Problem of Firms. - A representative firm on the unit interval seeks to solve the problem

$$
\begin{aligned}
Q\left(k, x_{M}, u_{M}, \epsilon\right)=\max _{\left(i_{m}(v)\right), \tilde{\ell}, k^{\prime}, x_{M^{\prime}}, u_{M^{\prime}}}\{ & G\left(k, x_{M}, z_{M} \tilde{\ell}\right)-W(\epsilon) \tilde{\ell}-p u_{M} \\
& -\left[k^{\prime}-\left(1-\delta_{s}\right) k\right]-\int i_{m}(v) \mathrm{d} v \\
& \left.+\mathbb{E}\left[\frac{\Psi(\epsilon)}{\Psi\left(\epsilon^{\prime}\right)+D\left(\epsilon^{\prime}\right)} Q\left(k^{\prime}, x_{M^{\prime}}, u_{M^{\prime}}^{\prime}, \epsilon^{\prime}\right)\right]\right\}
\end{aligned}
$$

subject to (a) the laws of motion of market energy services and use (9) and (10), where $x=$ $x_{M}, u=u_{M}$, and (b) the law of motion of the endogenous aggregate state $\left(\mathrm{k}^{\prime}, \mathrm{r}^{\prime}, \mathrm{x}_{M}^{\prime}, \mathrm{x}_{N}^{\prime}, \mathrm{u}_{M}^{\prime}, \mathrm{u}_{N}^{\prime}, \mathrm{s}^{\prime}\right)=$ $\Theta(\epsilon)$, taking as given the wage rate $W(\epsilon)$ and the discount factor $\Psi(\epsilon) /\left[\Psi\left(\epsilon^{\prime}\right)+D\left(\epsilon^{\prime}\right)\right]$ 
$[\mathrm{P}(4)]$.

To ease notation, define $A_{M} \equiv\left(K, X_{M}, U_{M}\right)$ and $A_{N} \equiv\left(\tilde{R}, X_{N}, U_{N}\right)$.

3. Definition of Equilibrium.-An equilibrium is a set of allocation functions for aggregate physical assets $\left(A_{M}, A_{N}\right)$, the financial asset $S$, the quantities $C, D, I_{d}, I_{m}$, and $L$, and pricing and transfer functions $\Psi, W$, and $T$, and an aggregate law of motion for endogenous states $\Theta(\epsilon)$ such that:

(i) Households solve problem $\mathrm{P}(3)$, taking as given the aggregate state of the world $\epsilon$, the allocation rule $D$, the pricing functions $\Psi$ and $W$, and transfer function $T$, and $\Theta(\epsilon)$, so that individual quantities are $c_{M}=C(\epsilon),\left(i_{d}(v)\right)=I_{d}(\epsilon), \ell=L(\epsilon)$, $\left(\tilde{r}^{\prime}, x_{N}{ }^{\prime}, u_{N}{ }^{\prime}\right)=A_{M}(\epsilon)$, and $\tilde{s}^{\prime}=S(\epsilon)=1$.

(ii) Firms solve problem $\mathrm{P}(4)$, taking as given the aggregate state of the world $\epsilon$, and the functions $D, \Psi, W$, and $\Theta(\epsilon)$, such that individual quantities are $\left(i_{m}(v)\right)=I_{m}(\epsilon)$, $\tilde{\ell}=L(\epsilon),\left(k^{\prime}, x_{M}{ }^{\prime}, u_{M}{ }^{\prime}\right)=A_{N}(\epsilon)$, and firms are equity-financed, $Q\left(k, x_{M}, u_{M}, \epsilon\right)=$ $(\Psi[\epsilon]+D[\epsilon]) \mathrm{s}$.

(iii) The resource constraint of the market consumption good holds in every period, that is,

$$
c_{M}+\int\left[i_{d}(v)+i_{m}(v)\right] \mathrm{d} v+i_{k}+i_{r}+p u_{M}+p u_{N}=G\left(k, x_{M}, z_{M} \ell\right),
$$

where

$$
i_{r}=\mathrm{r}^{\prime}-\left(1-\delta_{r}\right) \mathrm{r}, \quad i_{k}=\mathrm{k}^{\prime}-\left(1-\delta_{k}\right) \mathrm{k},
$$

and $\left(i_{m}(v)\right)$ govern the motion of market aggregate energy services and use, $\mathrm{x}_{M}^{\prime}=(1-$ $\left.\delta_{m}\right) \mathrm{x}_{M}+\int\left[f(v) q_{M} i_{m}(v) / v\right] \mathrm{d} v, \mathrm{u}_{M}^{\prime}=\left(1-\delta_{m}\right) \mathrm{u}_{M}+\int\left[q_{M} i_{m}(v) / v\right] \mathrm{d} v$, and $\left(i_{d}(v)\right)$ govern the motion of household energy services and use $\mathrm{x}_{N}^{\prime}=\left(1-\delta_{d}\right) \mathrm{x}_{N}+\int\left[h(v) q_{N} i_{m}(v) / v\right] \mathrm{d} v$, $\mathrm{u}_{N}^{\prime}=\left(1-\delta_{d}\right) \mathrm{u}_{N}+\int\left[q_{N} i_{m}(v) / v\right] \mathrm{d} v$.

\section{Equilibrium Behavior in Section VI.A}

Here we present the necessary equilibrium conditions useful in the calibration of the extended model with household production. We will utilize below the necessary conditions with respect to investment and the capital intensity of energy of new vintages. In the business sector, $q_{M} \mu_{x}=1 / f_{1}$ and $q_{M} \mu_{u}=\left[f-f_{1} v\right] / f_{1}$. In the household sector, the Lagrange multipliers $\varphi_{x}$ on (O.7) and $\varphi_{u}$ on (O.8) are determined by $q_{N} \varphi_{x}=U_{1} / h_{1}$ and $q_{N} \varphi_{u}=U_{1}\left[h-h_{1} v\right] / h_{1}$.

The allocation rules for $c_{M}, c_{N}, k^{\prime}, x_{M}{ }^{\prime}, u_{M}{ }^{\prime}, \tilde{r}^{\prime}, x_{N}{ }^{\prime}, u_{N}{ }^{\prime}, \ell$, and $d$, and pricing rule for $\psi$, in an equilibrium are implicit functions in the following system of equations. The Euler equations associated with the stocks of nonenergy-using capital, energy services, and energy used by firms are (A1)-(A3) with $q=q_{M}, x=x_{M}, z=z_{M}$. The Euler equations associated with the stocks of nonenergy-using capital, energy services, and energy used by households, and equity shares are: 


$$
\begin{aligned}
U_{1}\left(c_{M}, c_{N}\right)=\beta \mathbb{E}\left[U_{1}\left(c_{M}{ }^{\prime}, c_{N}{ }^{\prime}\right)(\right. & H_{1}\left(\tilde{r}^{\prime}, x_{N}{ }^{\prime}, z_{N}{ }^{\prime}\left(1-\ell^{\prime}\right)\right) \\
& \left.\left.\times \frac{U_{2}\left(c_{M}{ }^{\prime}, c_{N}{ }^{\prime}\right)}{U_{1}\left(c_{M^{\prime}}, c_{N}{ }^{\prime}\right)}+1-\delta_{r}\right)\right]
\end{aligned}
$$

$$
\frac{U_{1}\left(c_{M}, c_{N}\right)}{q_{N} h_{1}(v)}=\beta \mathbb{E}\left[U _ { 1 } ( c _ { M } { } ^ { \prime } , c _ { N } { } ^ { \prime } ) \left(H_{2}\left(\tilde{r}^{\prime}, x_{N}{ }^{\prime}, z_{N}{ }^{\prime}\left(1-\ell^{\prime}\right)\right)\right.\right.
$$

$$
\left.\left.\times \frac{U_{2}\left(c_{M}^{\prime}, c_{N}{ }^{\prime}\right)}{U_{1}\left(c_{M^{\prime}}, c_{N}{ }^{\prime}\right)}+\left(1-\delta_{d}\right) \frac{1}{q_{N}^{\prime} h_{1}\left(v^{\prime}\right)}\right)\right],
$$

$$
\begin{aligned}
U_{1}\left(c_{M}, c_{N}\right) \frac{h(v)-h_{1}(v) v}{q_{N} h_{1}(v)} & =\beta \mathbb{E}\left[U_{1}\left(c_{M^{\prime}},_{N_{N}}\right)\left(p^{\prime}+\left(1-\delta_{d}\right) \frac{h\left(v^{\prime}\right)-h_{1}\left(v^{\prime}\right) v^{\prime}}{q_{N^{\prime}} h_{1}\left(v^{\prime}\right)}\right)\right] \\
\psi U_{1}\left(c_{M}, c_{N}\right) & =\beta \mathbb{E}\left[\left(\psi^{\prime}+\left(1-\tau_{\delta}\right) \delta^{\prime}\right) U_{1}\left(c_{M^{\prime}}, c_{N}{ }^{\prime}\right)\right]
\end{aligned}
$$

where $v$ and $v^{\prime}$ denote the capital intensity of energy chosen by households. The efficiency condition of labor demand and supply is

$$
z_{M}\left(1-\tau_{w}\right) G_{3}\left(k, x_{M}, z_{M} \ell\right)=z_{N} H_{3}\left(\tilde{r}, x_{N}, z_{N}(1-\ell)\right) \frac{U_{2}\left(c_{M}, c_{N}\right)}{U_{1}\left(c_{M}, c_{N}\right)} .
$$

Together with the asset balancing condition (given in the equilibrium condition [ii]), the resource constraint (given in the equilibrium condition [iii]), and the laws of motion (7), (9), and (10), as well as (O.5), (O.7), and (O.8), the equations (A1)-(A3) and (O.9)-(O.13) define the allocation rules.

Analgous to the model in Section II, the households' and firms' problems $\mathrm{P}(3)$ and $\mathrm{P}(4)$ along with the resource constraint can be rewritten in terms of detrended variables in such a way that there is a unique stationary point in equilibrium. This allows us to calibrate the model with endogenous household production on a balanced growth path reflecting average observed growth.

\section{Equilibrium Balanced Growth in Section VI.A}

To calibrate the model so to match observed long-run growth of energy and output, we now analyze a deterministic steady-state equilibrium path.

Change in Energy Use, Efficiency, and Services.-We first assemble the growth factors necessary to express energy efficiency and services change needed to utilize the basic idea. 
Investment-specific technological change expressed by

$$
\gamma_{q_{i}}=\text { gross rate of change in } q_{i} \text { for } i \in\{M, N\} \text {, }
$$

implies that energy-using capital $\int m(v) \mathrm{d} v$ and $\int d(v) \mathrm{d} v$ grow at the gross rates $g \gamma_{q_{M}}$ and $g \gamma_{q_{N}}$, denoting by $g$ the growth factor of output in (O.6). Constant energy expenditure $p e / y$ implies the growth rate of energy use $-u_{M}$ and $u_{N}$ - equal to $g \gamma_{1 / p}$. The symmetric puttyclay structure of production in the market and households implies that the capital-energy ratio of new energy-using capital changes at the same rate as aggregate capital relative to aggregate energy changes - equal to the ratio of the growth rate of sectoral investmentspecific technology and the inverse of the rate of change in the energy price, implying the growth factor of energy efficiency $\left(\gamma_{q_{i}} / \gamma_{1 / p}\right)^{\varepsilon_{i}}$ for $i \in\{M, N\}$. The laws of motion of services (9) and (O.7) then imply that energy services $x_{i}$ grow at the rate $g \gamma_{q_{i}}{ }^{\varepsilon_{i}} \gamma_{1 / p}{ }^{1-\varepsilon_{i}}$ for $i \in\{M, N\}$.

With the growth rate of investment-specific productivity $q_{M}$ given by $\gamma_{q}=\gamma_{q_{M}}$ and labor efficiency in the market $z_{M}$ given by $\gamma_{z}=\gamma_{z_{M}}$, market output changes at the gross rate $(14){ }^{44}$

Output-Capital Ratios. - We will now rewrite the equations determining equilibrium behavior so to find parameter values. Equations (18)-(21) govern nonenergy-using capital, and investment and the capital-energy ratio of energy-using capital in the market (yielding $x=x_{M}, u=u_{M}$ ). These equations may be written with $q=q_{M}, \varepsilon=\varepsilon_{M}$, and $\phi=\phi_{M}$, $\theta=\theta_{M}$. Added to the corresponding first-order necessary conditions are now conditions for nonenergy-using capital, and investment and the capital intensity type of energy for energy-using capital in households. The deterministic balanced growth path analogues to the Euler equations of these stocks chosen by households given in Appendix D are

$$
\begin{gathered}
1=(1 / R)\left\{\lambda \zeta(y / \tilde{r})\left(c_{N} / y\right) \frac{U_{2}}{U_{1}}+1-\delta_{r}\right\}, \\
\gamma_{q_{N}}=(1 / R)\left\{\lambda \varepsilon_{N}(1-\zeta)[\underbrace{\left(\frac{q_{N}^{\prime} y^{\prime}}{x_{N}^{\prime}}\right) \frac{h(v)}{v}}_{\phi_{N}^{\prime}}]\left(c_{N} / y\right) \frac{U_{2}}{U_{1}}+\left(1-\delta_{d}\right)\left(\gamma_{q_{N}} / \gamma_{1 / p}\right)^{\varepsilon_{N}}\right\}, \\
\gamma_{q_{N}}=(1 / R)\left\{\frac{\varepsilon_{N}}{1-\varepsilon_{N}}[\underbrace{\left(\frac{q_{N}^{\prime} y^{\prime}}{u_{N}^{\prime}}\right) \frac{1}{v}}_{\theta_{N}^{\prime}}]\left(p u_{N} / y\right)+\left(1-\delta_{d}\right)\left(\gamma_{q_{N}} / \gamma_{1 / p}\right)\right\},
\end{gathered}
$$

\footnotetext{
${ }^{44}$ For each set of rates of change in the energy price $1 / \gamma_{1 / p}$, investment-specific productivity $\left(\gamma_{q_{M}}, \gamma_{q_{N}}\right)$, and market and household output, there are rates of labor efficiency change $\left(\gamma_{z_{M}}, \gamma_{z_{N}}\right)$ consistent with a deterministic balanced growth path.
} 
using the marginal utility of consumption $U_{i}$, the derivative of $U$ with respect to its $i$ th argument. The laws of motion of the stocks of nonenergy-using capital, energy services, and energy use (O.5), (O.7), and (O.8), imply that

$$
\begin{gathered}
i_{r} / y=\left[g-\left(1-\delta_{r}\right)\right] /(y / \tilde{r}), \\
\int\left[i_{d}(v) / y\right] \mathrm{d} v=\left[g \gamma_{q_{N}}-\left(1-\delta_{d}\right)\left(\gamma_{q_{N}} / \gamma_{1 / p}\right)^{\varepsilon_{N}}\right] / \phi_{N}, \\
\int\left[i_{d}(v) / y\right] \mathrm{d} v=\left[g \gamma_{q_{N}}-\left(1-\delta_{d}\right)\left(\gamma_{q_{N}} / \gamma_{1 / p}\right)\right] / \theta_{N},
\end{gathered}
$$

with the capital intensity of energy chosen by households $v$.

In both the market and nonmarket sector, new vintages' and average capital-service and capital-energy ratios change at the same rate so that the corresponding relative ratios are constant, where capital corresponds to energy-using capital. Defining $\mathrm{f}_{M}=f$ and $\mathrm{f}_{N}=h$, the ratio $\phi_{i} / \theta_{i}=\mathrm{f}_{i}(v) /\left(x_{i} / u_{i}\right)$ expresses the technological gap between energy efficiency in the youngest vintages and average practice in sector $i \in\{M, N\}$.

Remaining are conditions for the allocation of equity holdings, time to market and home production, substitution of market and home consumption goods, and the use of market output: (23),

$$
\begin{gathered}
\left(1-\tau_{w}\right)(1-\alpha)[(1-\ell) / \ell]=(1-\lambda)[(1-\xi) / \xi]\left(c_{M} / y\right), \\
c_{M} / y+\int\left[i_{m}(v) / y\right] \mathrm{d} v+i_{k} / y+\int\left[i_{d}(v) / y\right] \mathrm{d} v+i_{r} / y+p u_{M} / y+p u_{N} / y=1 .
\end{gathered}
$$

The necessary condition governing the allocation of time (O.20) uses the marginal rate of substitution between market and home consumption goods $U_{2} / U_{1}=[(1-\xi) / \xi]\left(\left[c_{M} / y\right] /\left[c_{N} / y\right]\right)$. The resource constraint (stated in the equilibrium condition [iii]) can be rewritten as (O.21).

To evaluate the efficiency paradox, we will now use these equations to calibrate the model mirroring observed long-run growth of energy and output.

\section{Calibration of Model with Household Production}

The important parameters for rebound and savings of energy used in households are $\gamma_{q_{N}}$ and $\varepsilon_{N}$. We now report the full calibration of the model including of values for these parameters.

Household production introduces six new parameters and makes redundant one parameter relative to the model in Section II, so that we need to select values for $\beta$ and $\xi$ for preferences, $\alpha, \gamma, \varepsilon_{M}, \lambda, \zeta$, and $\varepsilon_{N}$ for production, $\delta_{d}, \delta_{k}, \delta_{m}$, and $\delta_{r}$ for the depreciation of capital, $\gamma_{q_{M}}, \gamma_{q_{N}}, \gamma_{1 / p}$, for the capital and energy price changes, and $\tau_{\delta}$ and $\tau_{w}$ for government policy. The following empirical moments are useful to directly pick val- 
ues: (i) Depreciation rates for capital used in households, M14 and M15. Interpreting energy-using capital used in households as durable consumption goods, we set $\delta_{d}$ equal to the depreciation rate for durable consumption goods in the data. We measure nonenergyusing capital used in households as private residential structures capital. Analogous to the procedure to compute geometric depreciation rates for business capital we obtain 23.2 percent and 3.3 percent. (ii) Long-run change in durable goods productivity, M16. The deflator for consumption relative to the deflator for expenditures on durable consumption goods has steadily increased, at 3.2 percent on average per year, as reported in Appendix A, giving $\gamma_{q_{N}}$.

We set directly the values for $\delta_{d}, \delta_{m}, \delta_{k}, \delta_{r}, \gamma_{q_{M}}, \gamma_{q_{N}}, \gamma_{1 / p}, \alpha$, and $\tau_{w}$ using the moments M1-M6 and M14-M16:

\begin{tabular}{lccc}
\hline Parameter & $\delta_{d}$ & $\delta_{r}$ & $\gamma_{q_{N}}$ \\
Value & 0.232 & 0.033 & 1.032 \\
\hline
\end{tabular}

and the values for parameters not listed here equal to those values in Section IV.B (with $\left.\gamma_{q}=\gamma_{q_{M}}\right)$.

To determine the remaining parameter values, we require the following additional empirical moments: (i) Investment-output ratios, M17 and M18. The mean of investment relative to GNP (net of gross housing product) is 9.6 percent related to durable consumption goods and 5.2 percent to private residential structures $\left(\int\left[i_{d}(v) / y\right] \mathrm{d} v=0.096\right.$ and $\left.i_{r} / y=0.052\right)$. (ii) Energy expenditure, M19. Energy expenditure by households relative to the value of market goods given by GNP (net of owner-occupied housing product) has been on average 2.7 percent $\left(p u_{N} / y=0.027\right)$.

We obtain the values for the remaining parameters $\beta, \xi, \varepsilon_{M}, \gamma, \lambda, \varepsilon_{N}, \zeta$, and $\tau_{\delta}$, and the ratios of some economic variables, using the moments M7-M12 and M17-M19 together with the equilibrium conditions (21)-(23) and (O.14)-(O.21):

\begin{tabular}{lccc}
\hline Parameter & $\lambda$ & $\zeta$ & $\varepsilon_{N}$ \\
Value & 0.14 & 0.38 & 0.80 \\
\hline
\end{tabular}

and values for parameters not listed here as before, and $(y / r)=0.89, \phi_{N}=2.83, \theta_{N}=2.58$, $\left(c_{M} / y\right)=0.69$, as well as $(y / k), \phi=\phi_{M}, \theta=\theta_{M}$ as before. The values for the parameters governing production in the market are unchanged (with $\varepsilon_{M}=\varepsilon$ ). Again, we have used one more moment than we have determined parameters until determining the rate of labor efficiency change in the market $\left(\gamma_{z}=\gamma_{z_{M}}\right)$.

The derived value $\left(c_{N} / y\right) U_{2} / U_{1}=1.57$ implies that gross economic product $G+H U_{2} / U_{1}$ relative to value added in the market $G$ along the balanced growth path is 2.57 , which is close to the value of 2.9 obtained by Greenwood and Hercowitz (1991).

\section{Robustness: Capital Utilization}

We here provide conditions used in evaluating the utilization of energy-using capital. The cutoff level of energy efficiency below which underutilization of energy-using capital is rational in market production $f\left(v^{*}\right)$ is given by $G_{2}\left(k, x_{M}, z_{M} \ell\right)=p / f\left(v^{*}\right)$. 
Analogously, the cutoff level of energy efficiency in household production $h\left(v^{*}\right)$ is determined by $H_{2}\left(\tilde{r}, x_{N}, z_{N}(1-\ell)\right) U_{2} / U_{1}=p / h\left(v^{*}\right)$. These two conditions are analogous to Equation (15) in Atkeson and Kehoe (1999). The conditions can be developed into $\alpha_{M}\left(1-\gamma_{M}\right) y / x_{M}=p / f\left(v^{*}\right)$ and $\lambda(1-\zeta)\left(y / x_{N}\right)\left(c_{N} / y\right) U_{2} / U_{1}=p / h\left(v^{*}\right)$. Clearly, the left side decreases over time during balanced growth with capital intensity increase so that the cutoff level increases over time. We find the capital intensity of energy in households $v$ as residual from the laws of motion (O.4) and (O.8) and evaluate $h\left(v^{*}\right)$ with $z_{N}=z_{M}$ and the steady-state level of $U_{2} / U_{1}$. 


\section{Working Papers of the Center of Economic Research at ETH Zurich}

(PDF-files of the Working Papers can be downloaded at www.cer.ethz.ch/research/workingpapers.html).

18/299 S. Rausch and H. Schwerin

Does Higher Energy Efficiency Lower Economy-Wide Energy Use?

18/298 H. Gersbach, U. Schetter and M. Schneider

Economic Rationales for Investments in Science

18/297 K. Borissov and L. Bretschger

Optimal Carbon Policies in a Dynamic Heterogenous World

18/296 L. Bretschger and C. Karydas

Economics of Climate Change: Introducing the Basic Climate Economic (BCE) Model

18/295 A. Pattakou and A. Vlahakis

Effectiveness of renewable energy subsidies in a CO2 intensive electricity system

18/294 H. Gersbach, V. Hahn and Y. Liu

Macroprudential Policy in the New Keynesian World

18/293 H. Schwerin

Swap Bonds or Stocks, or Balance Trade! A Game of Implicit Environmental Policy

18/292 S. Houde

Bunching with the Stars: How Firms Respond to Environmental Certification

18/291 L. Bretschger and A. Vinogradova

Escaping Damocles' Sword: Endogenous Climate Shocks in a Growing Economy

18/290 S. Houde

The Incidence of Coarse Certification: Evidence from the ENERGY STAR Program

18/289 J. Blasch, N. Boogen, C. Daminato and M. Filippini

Empower the consumer! Energy-related financial literacy and its socioeconomic determinants

18/288 L. Bretschger and S. Soretz

Stranded Assets: How Policy Uncertainty affects Capital, Growth, and the Environment

18/287 S. Rausch and H. Yonezawa

The Intergenerational Incidence of Green Tax Reform 
18/286 J. Abrell, S. Rausch, and C. Streitberger

The Economics of Renewable Energy Support

18/285 K. Borissov, L. Bretschger and A. Vinogradova

Carbon Pricing, Technology Transition, and Skill-Based Development

17/284 H. Gersbach, A. Mamageishvili and O. Tejada

Assessment Voting in Large Electorates

17/283 H. Gersbach, A. Mamageishvili and O. Tejada

Sophisticated Attacks on Decoy Ballots: A Devil's Menu and the Market for Lemons

17/282 S. Houde, J. E. Aldy

The Efficiency Consequences of Heterogeneous Behavioral Responses to Energy Fiscal Policies

17/281 Chiara Colesanti Senni

Energy Transition, Technological Spillovers and Elasticity of Substitution

17/280 Anna Alberini, Olha Khymych and Milan Scasny

Response to Extreme Energy Price Changes: Evidence from Ukraine

17/279 M. Filippini, G. Masiero and S. Steinbach

The Impact of Ambient Air Pollution on Hospital Admissions

17/278 M. Filippini and T. Wekhof

The Effect of Culture on Energy Efficient Vehicle Ownership

17/277 L. Bretschger, A. Pattakou

As Bad as it Gets: How Climate Damage Functions Affect Growth and the Social Cost of Carbon

17/276 J. Blasch, M. Filippini, N. Kumar, A. Martinez.Cruz

Narrowing the energy efficiency gap: The impact of educational programs, online support tools and energy-related investment literacy

17/275 M. Filippini, W. Greene, N. Kumar, A. Martinez.Cruz

A note on the different interpretation of the correlation parameters in the Bivariate Probit and the Recursive Bivariate Probit

17/274 D. Basin, H. Gersbach, A. Mamageishvili, L. Schmid and O. Tejada

Election Security and Economics: It's all about Eve

17/273 J. Abrell, M. Kosch and S. Rausch

The Economic Cost of Carbon Abatement with Renewable Energy Policies

17/272 H. Gersbach and O. Tejada

Semi-Flexible Majority Rules for Public Good Provision 
17/271 D. Cerruti, A. Alberini, J. Linn

Charging Drivers by the Pound: The Effects of the UK Vehicle Tax System

17/270 H. Gersbach, P. Muller, O. Tejada

A Dynamic Model of Electoral Competition with Costly Policy Changes

17/269 J. Blasch, N. Boogen, M. Filippini, N. Kumar

The role of energy and investment literacy for residential electricity demand and end-use efficiency

17/268 H. Gersbach, M.-C. Riekhof

Technology Treaties and Climate Change

17/267 Christos Karydas

The inter-temporal dimension to knowledge spillovers: any non-environmental reason to support clean innovation?

17/266 Christos Karydas, Lin Zhang

Green tax reform, endogenous innovation and the growth dividend

17/265 Daniel Harenberg, Stefano Marelli, Bruno Sudret, Viktor Winschel

Uncertainty Quantification and Global Sensitivity Analysis for Economic Models

16/264 Marie-Catherine Riekhof

The Insurance Premium in the Interest Rates of Interlinked Loans in a Small-scale Fishery

16/263 Julie Ing

Adverse selection, commitment and exhaustible resource taxation

16/262 Jan Abrell, Sebastian Rausch, and Giacomo A. Schwarz

Social Equity Concerns and Differentiated Environmental Taxes

16/261 D. Ilic, J.C. Mollet

Voluntary Corporate Climate Initiatives and Regulatory Loom: Batten Down the Hatches

16/260 L. Bretschger

Is the Environment Compatible with Growth? Adopting an Integrated Framework

16/259 V. Grossmann, A. Schaefer, T. Steger, and B. Fuchs

Reversal of Migration Flows: A Fresh Look at the German Reunification 